\title{
Palladium-catalyzed Coupling of Terminal Alkynes with Benzyl
}

\section{Ammonium Salts}

Silin Xu, Zhenming Zhang, Chunyu Han, Wenkai Hu, Tiwen Xiao, Yanan Yuan, Junfeng Zhao*

College of Chemistry and Chemical Engineering, Jiangxi Normal University, Nanchang, 330022, P. R. China

Email: zhaojf@jxnu.edu.cn

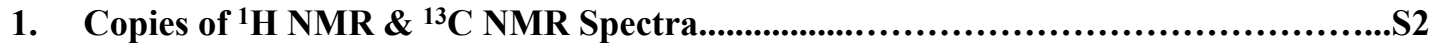




\section{Copies of ${ }^{1} \mathrm{H}$ NMR \& ${ }^{13} \mathrm{C}$ NMR Spectra}
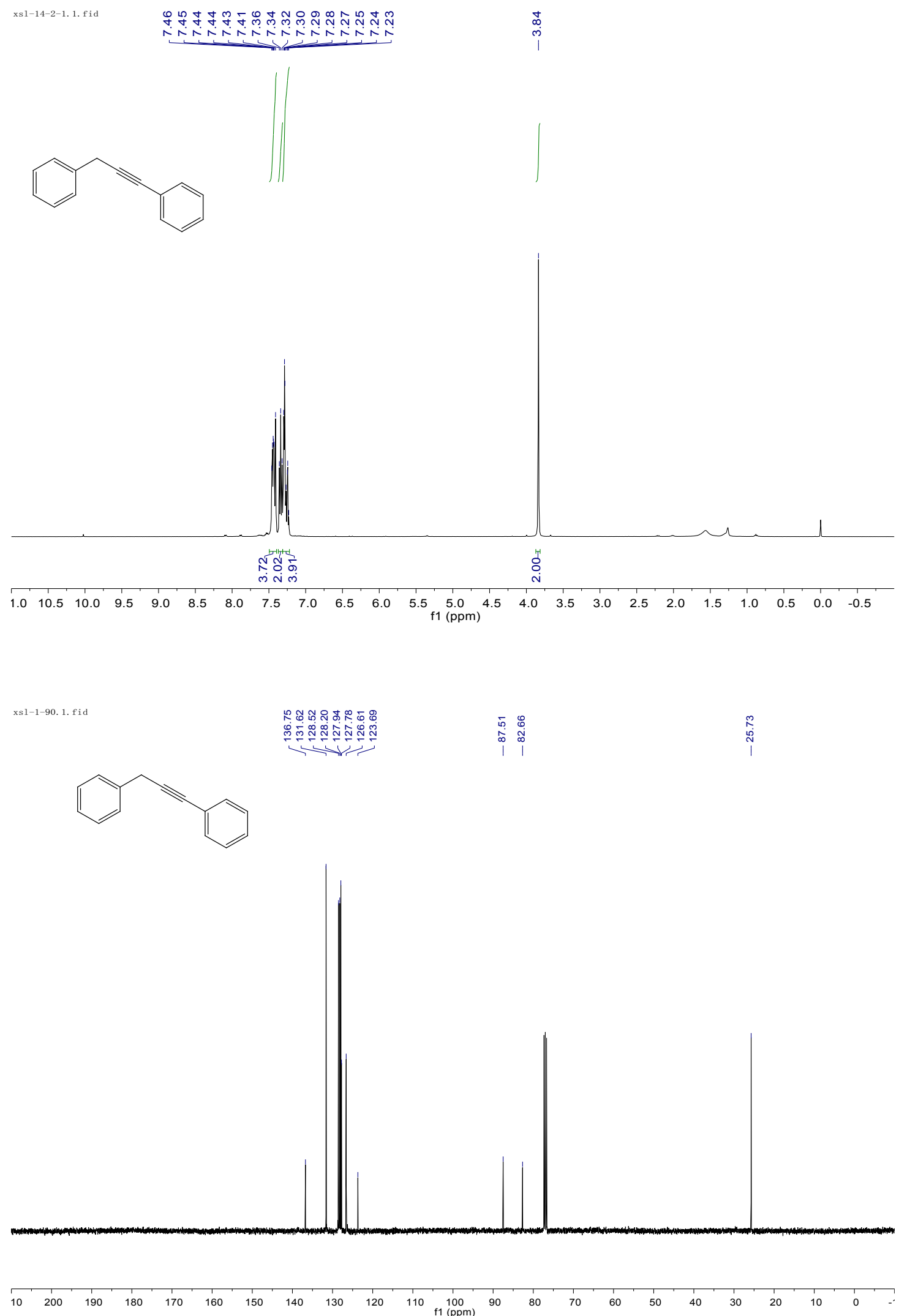

${ }^{1} \mathrm{H}$ NMR and ${ }^{13} \mathrm{C}$ NMR for compound 3aa 


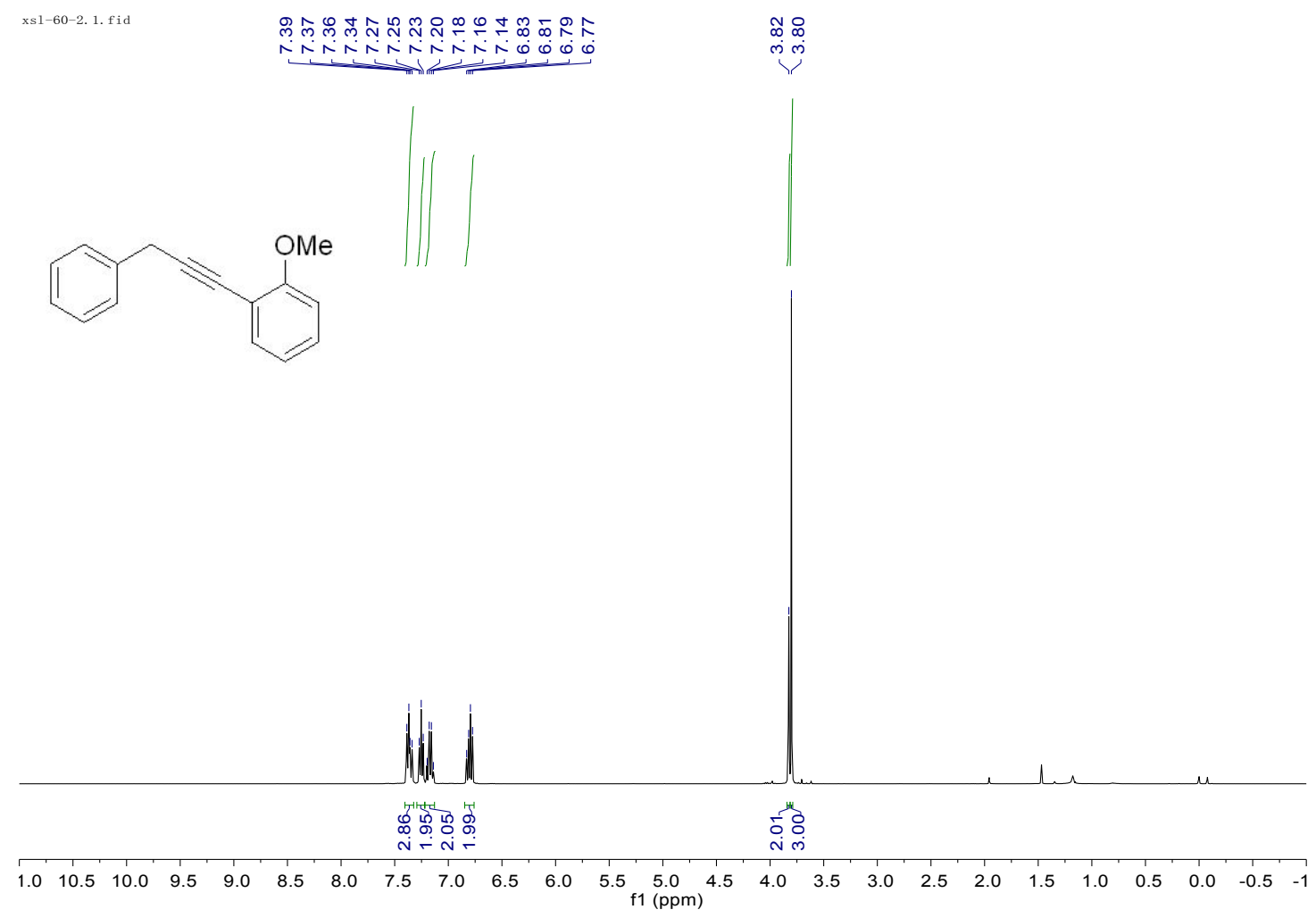

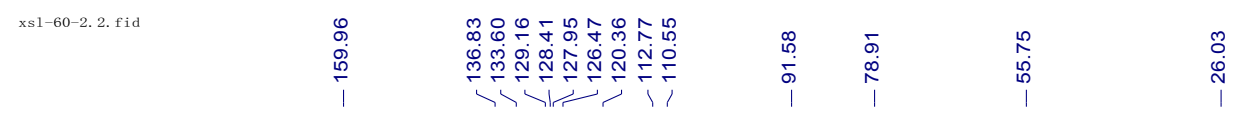

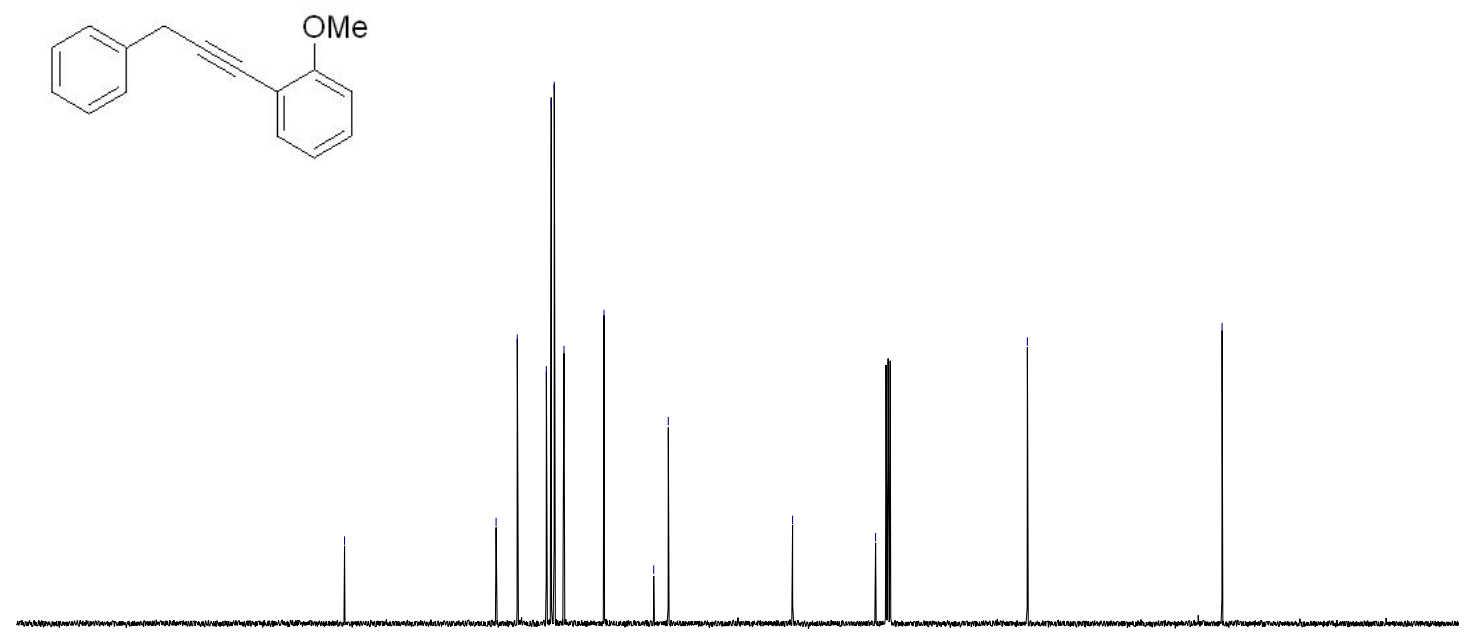

\begin{tabular}{lllllllllllllllllllllllllll}
\hline 10 & 200 & 190 & 180 & 170 & 160 & 150 & 140 & 130 & 120 & 110 & 100 & 90 & 80 & 70 & 60 & 50 & 40 & 30 & 20 & 10 & 0 & -
\end{tabular}

${ }^{1} \mathrm{H}$ NMR and ${ }^{13} \mathrm{C}$ NMR for compound 3ab 


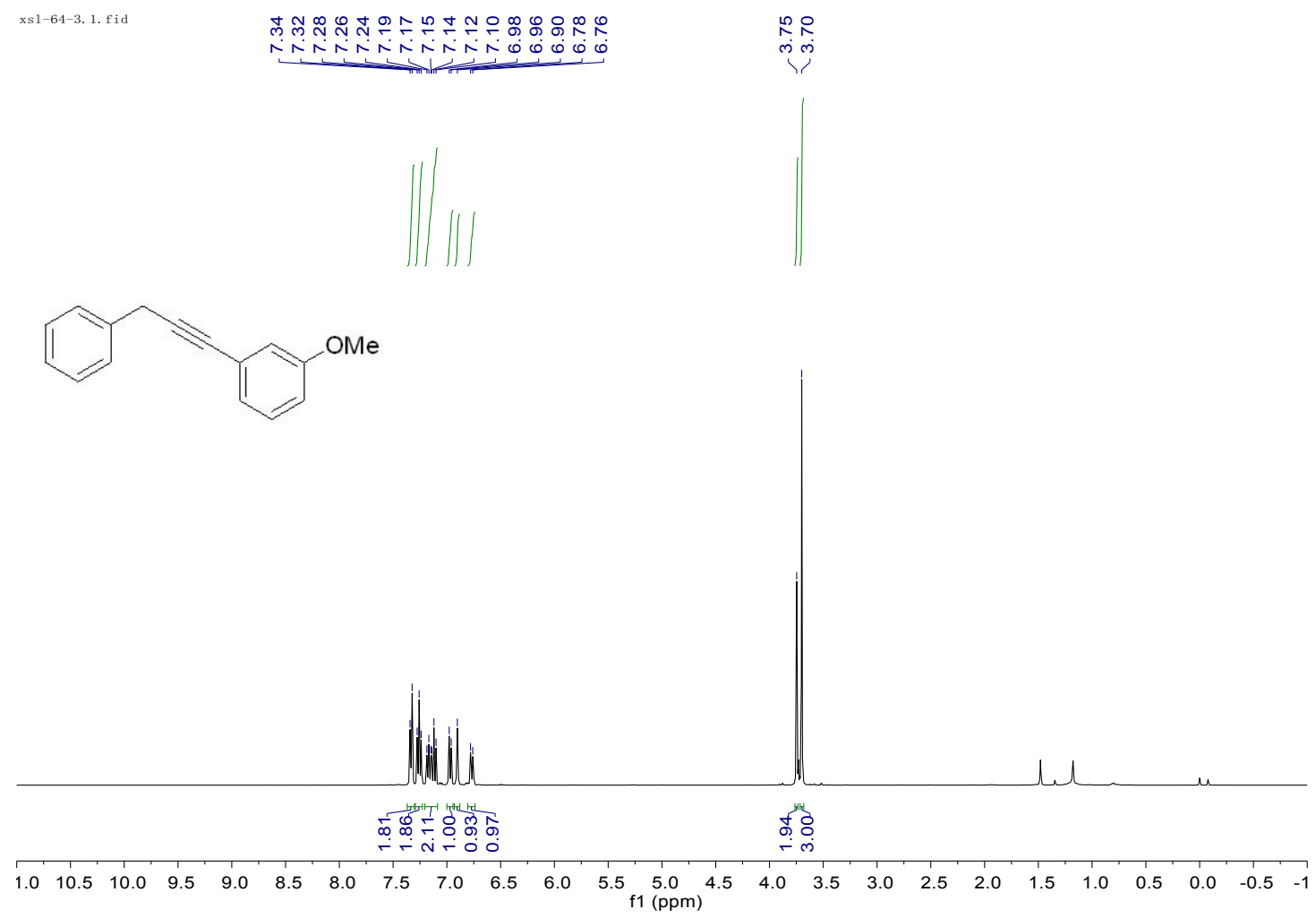

\begin{tabular}{|c|c|c|c|c|c|}
\hline $\mathrm{xsl}-64-3.2 . \mathrm{fid}$ & 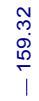 & 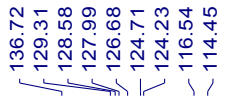 & 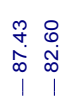 & $\begin{array}{c}\hat{N} \\
\stackrel{0}{0} \\
1\end{array}$ & $\begin{array}{l}0 \\
1\end{array}$ \\
\hline
\end{tabular}

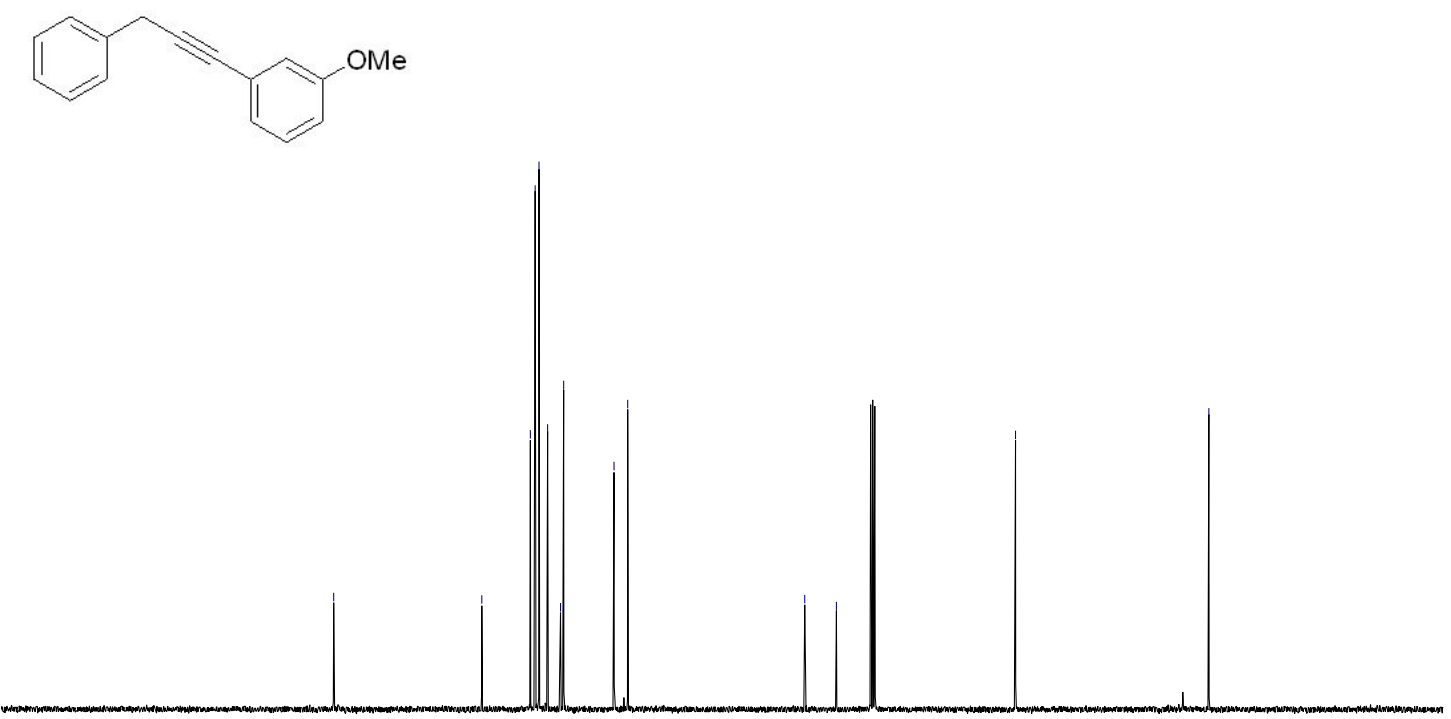

\begin{tabular}{llllllllllllllllllllllllll}
\hline 10 & 200 & 190 & 180 & 170 & 160 & 150 & 140 & 130 & 120 & 110 & 100 & 90 & 80 & 70 & 60 & 50 & 40 & 30 & 20 & 10 & 0 & -
\end{tabular}

${ }^{1} \mathrm{H}$ NMR and ${ }^{13} \mathrm{C}$ NMR for compound 3 ac 

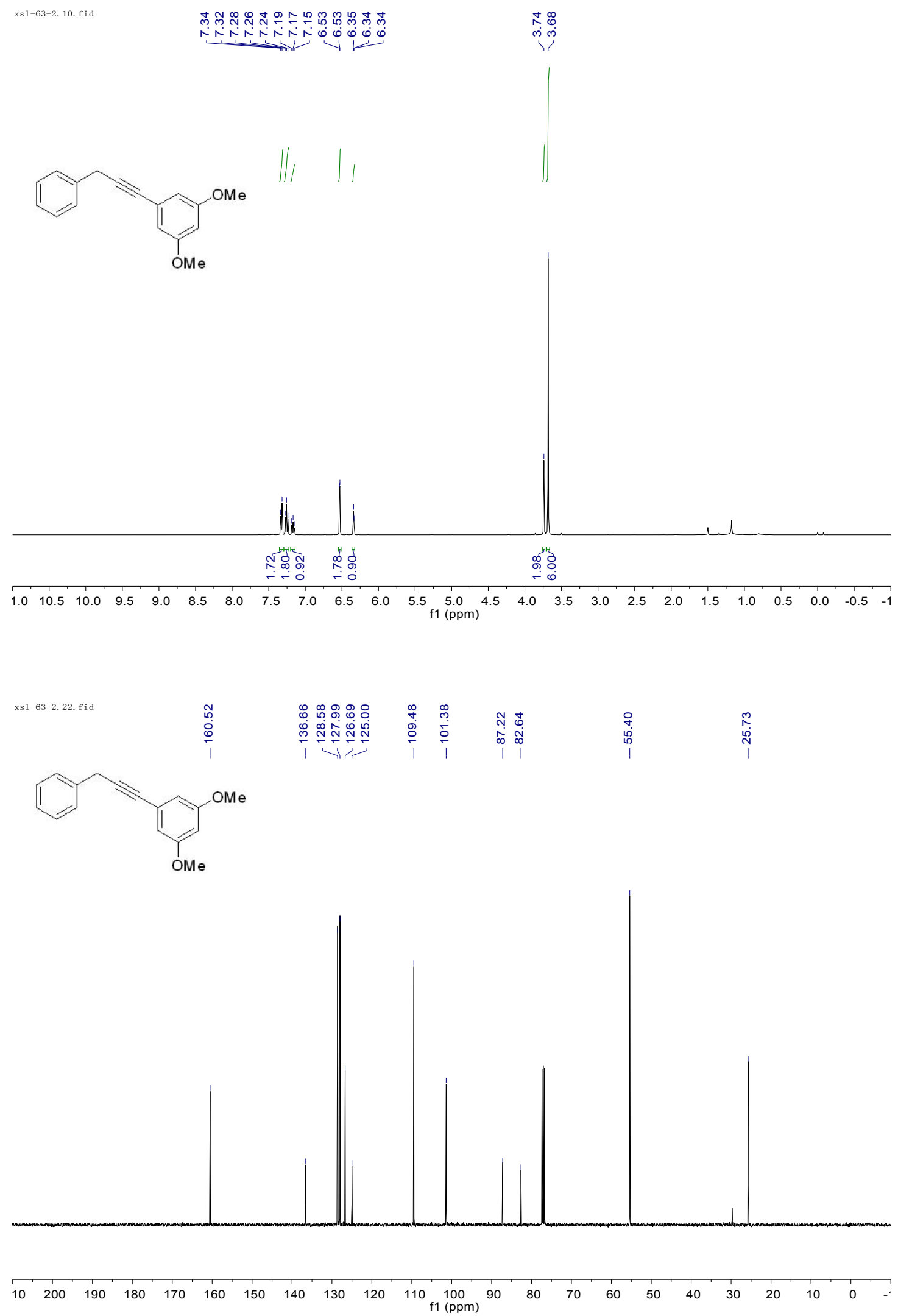

${ }^{1} \mathrm{H}$ NMR and ${ }^{13} \mathrm{C}$ NMR for compound 3ad 

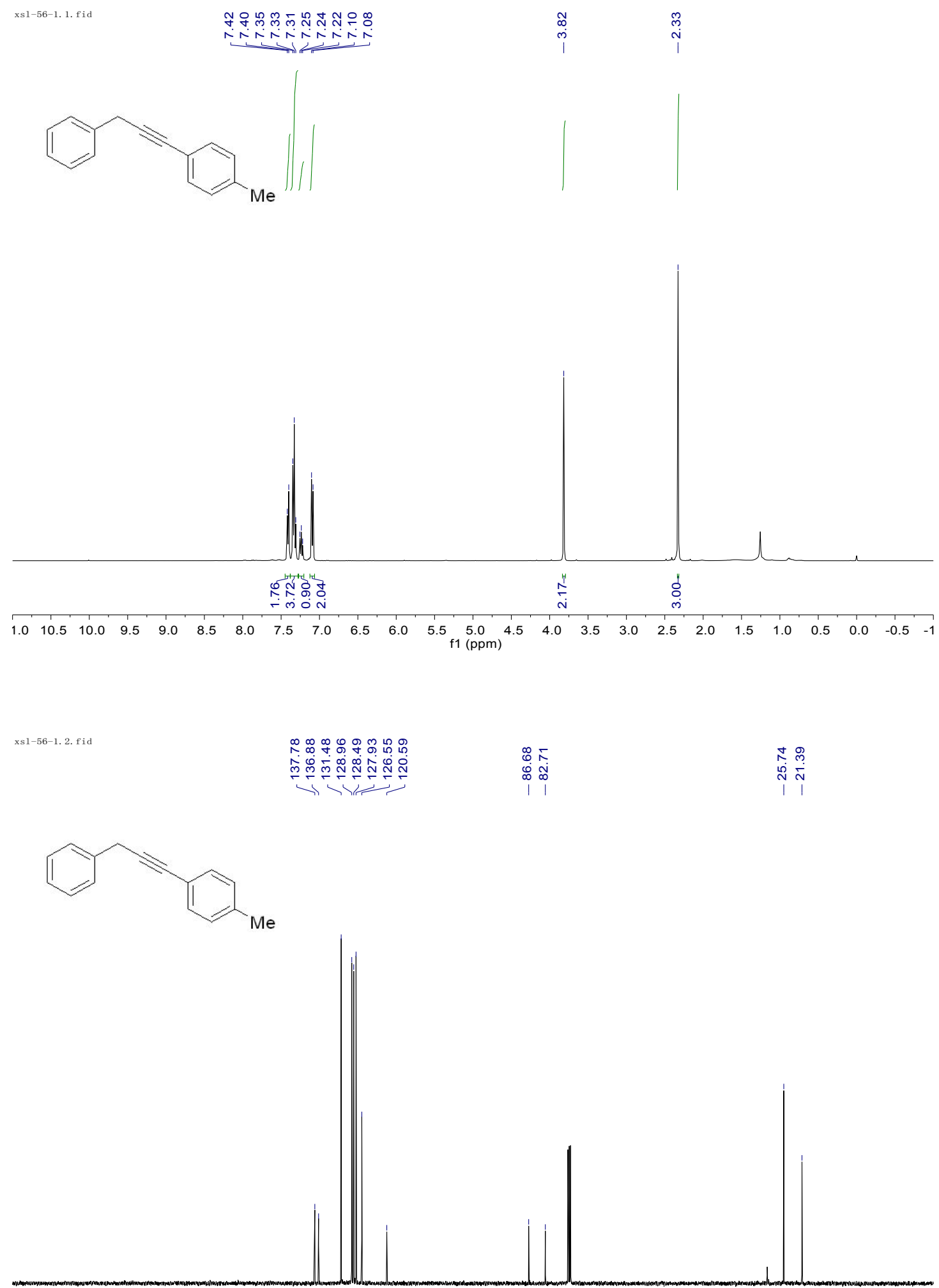

\begin{tabular}{llllllllllllllllllllllll}
\hline 10 & 200 & 190 & 180 & 170 & 160 & 150 & 140 & 130 & 120 & 110 & 100 & 90 & 80 & 70 & 60 & 50 & 40 & 30 & 20 & 10 & 0 & -
\end{tabular}

${ }^{1} \mathrm{H}$ NMR and ${ }^{13} \mathrm{C}$ NMR for compound 3ae 


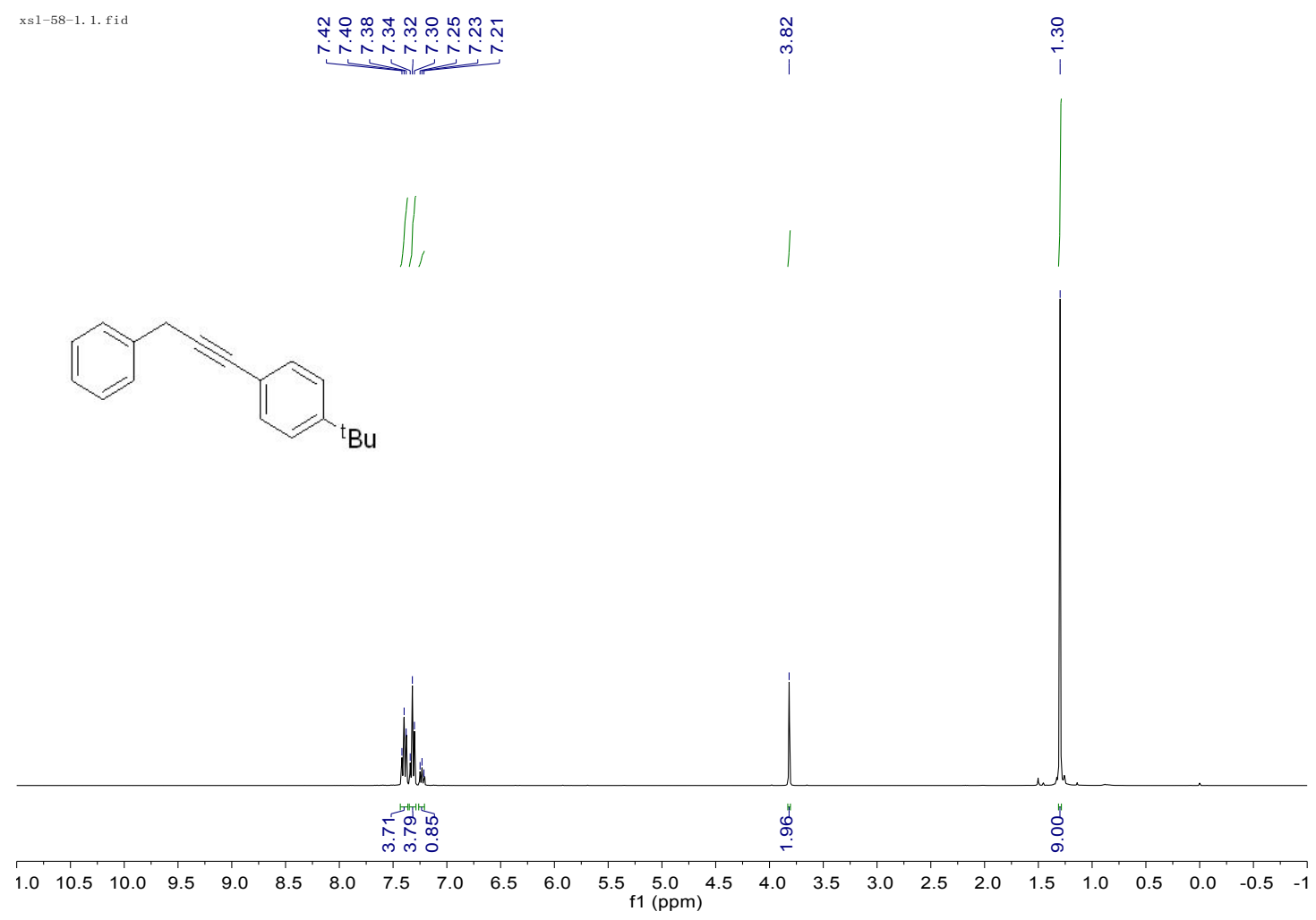

\begin{tabular}{|c|c|c|c|c|}
\hline $\mathrm{xs} 1-58-1.2 . \mathrm{fid}$ & $\begin{array}{l}\hat{\sigma} \\
\text { ○े } \\
\text { ம} \\
\text { । }\end{array}$ & 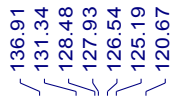 & 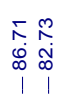 & 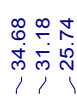 \\
\hline
\end{tabular}<smiles>CC(C)(C)c1ccc(C#CCc2ccccc2)cc1</smiles>

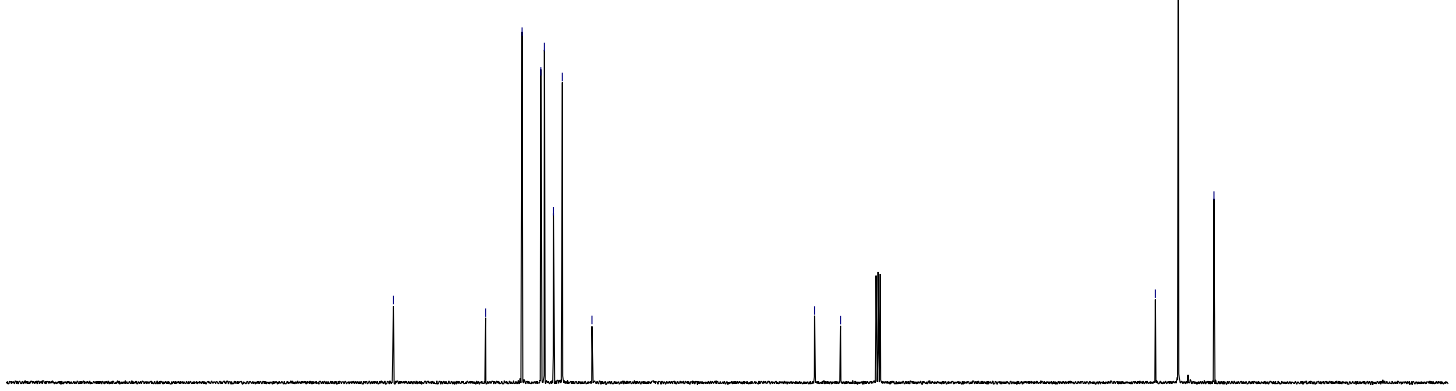

\begin{tabular}{lllllllllllllllllllllllll}
\hline 10 & 200 & 190 & 180 & 170 & 160 & 150 & 140 & 130 & 120 & 110 & 100 & 90 & 80 & 70 & 60 & 50 & 40 & 30 & 20 & 10 & 0 & -
\end{tabular}

${ }^{1} \mathrm{H}$ NMR and ${ }^{13} \mathrm{C}$ NMR for compound 3af 


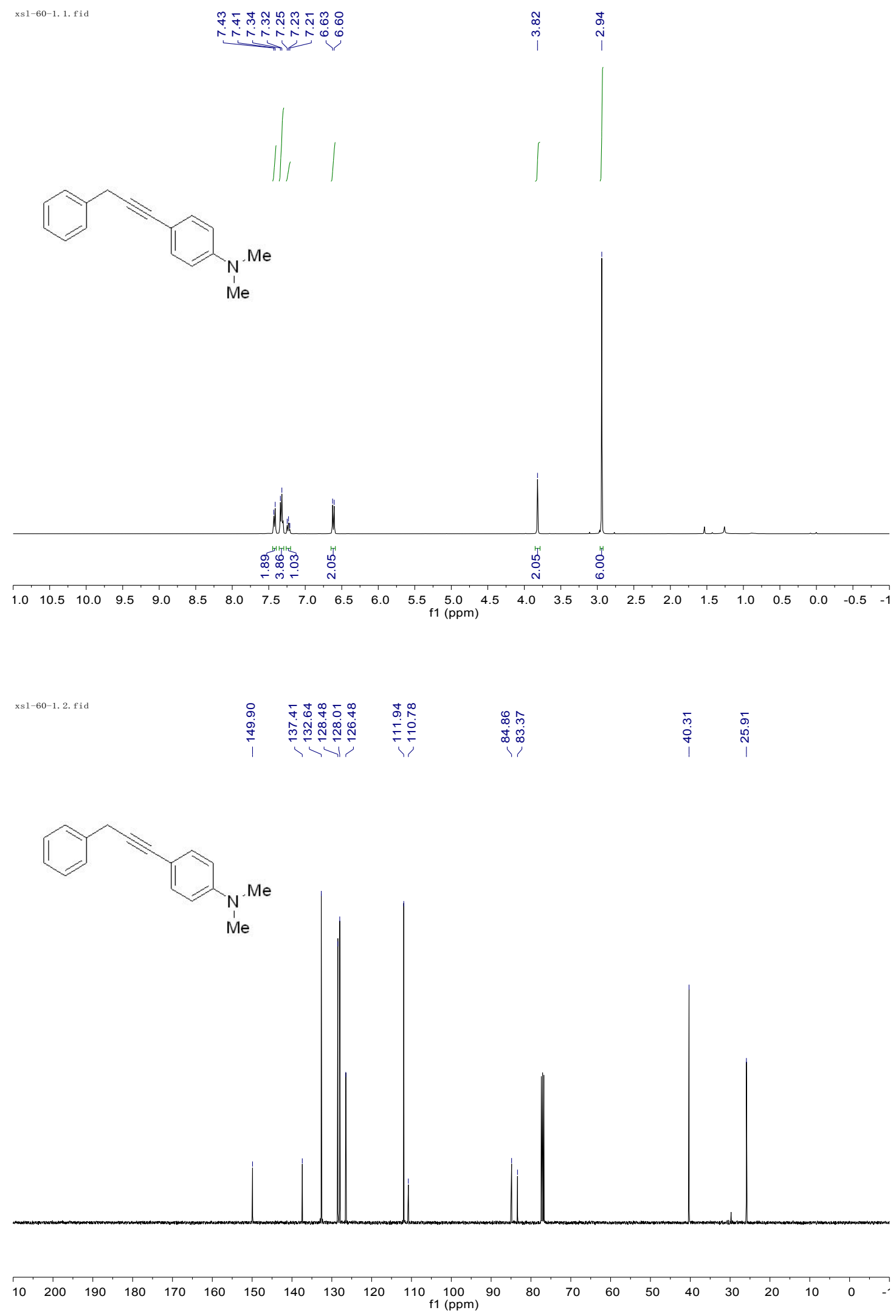

${ }^{1} \mathrm{H}$ NMR and ${ }^{13} \mathrm{C}$ NMR for compound $\mathbf{3 a g}$ 


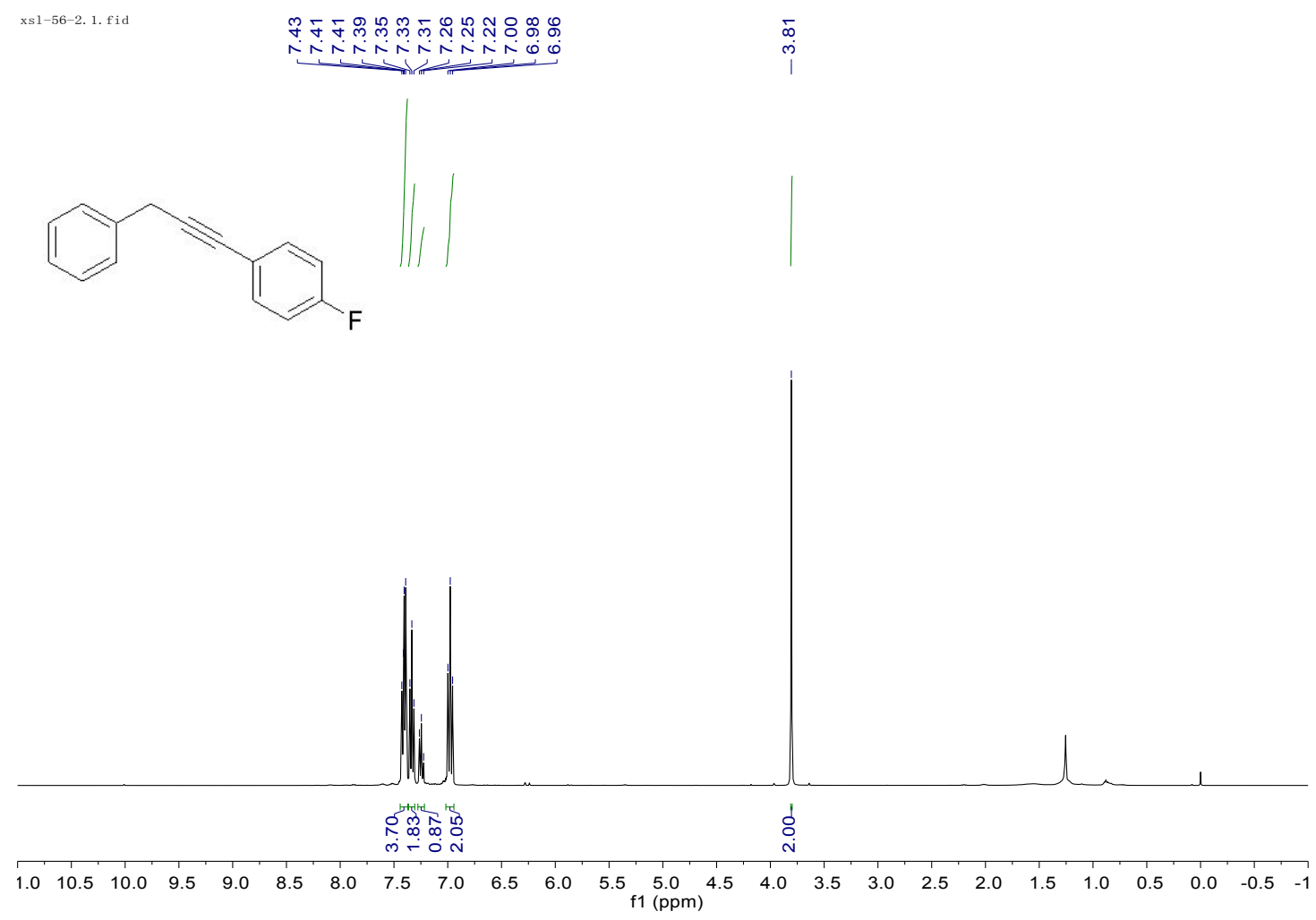

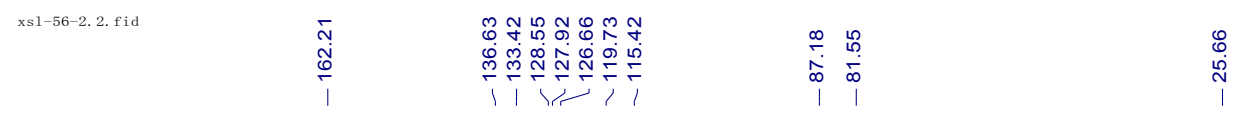

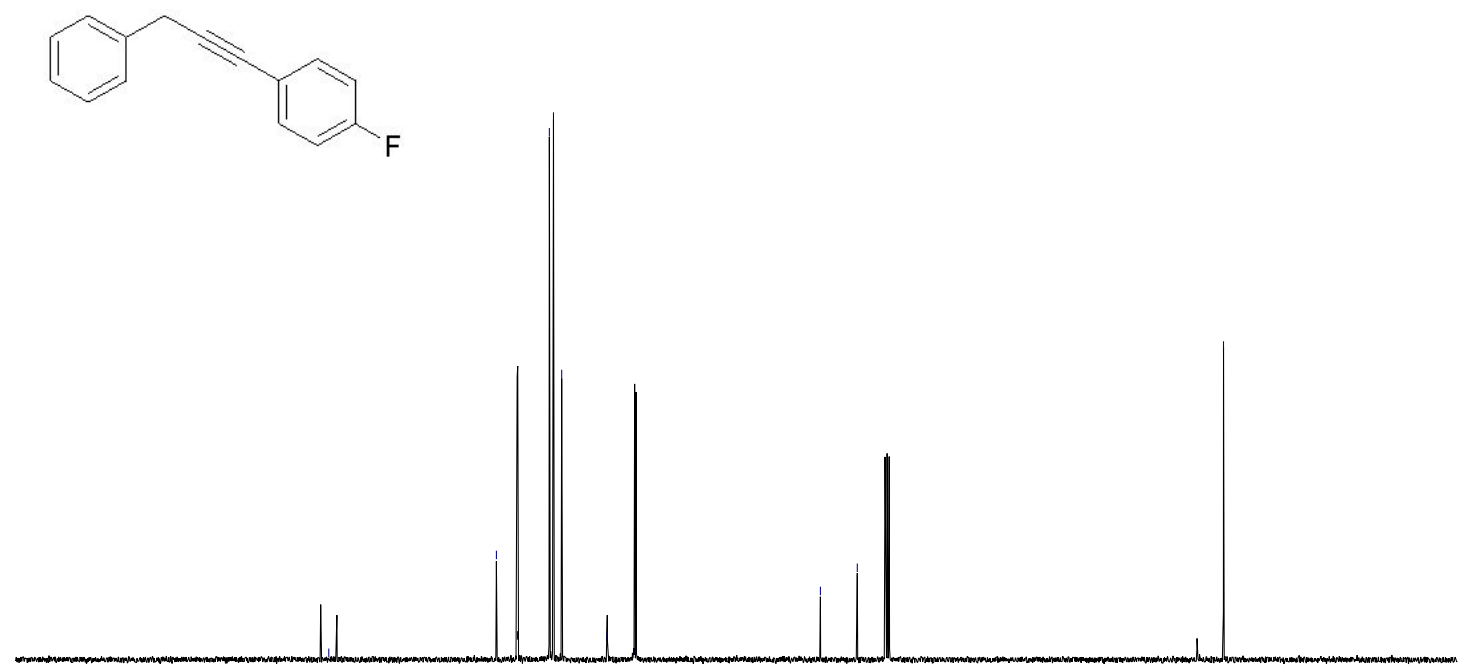

$\begin{array}{lllllllllllllllllllllll}10 & 200 & 190 & 180 & 170 & 160 & 150 & 140 & 130 & 120 & 110 & 100 & 90 & 80 & 70 & 60 & 50 & 40 & 30 & 20 & 10 & 0 & \cdots\end{array}$

${ }^{1} \mathrm{H}$ NMR and ${ }^{13} \mathrm{C}$ NMR for compound 3ah 

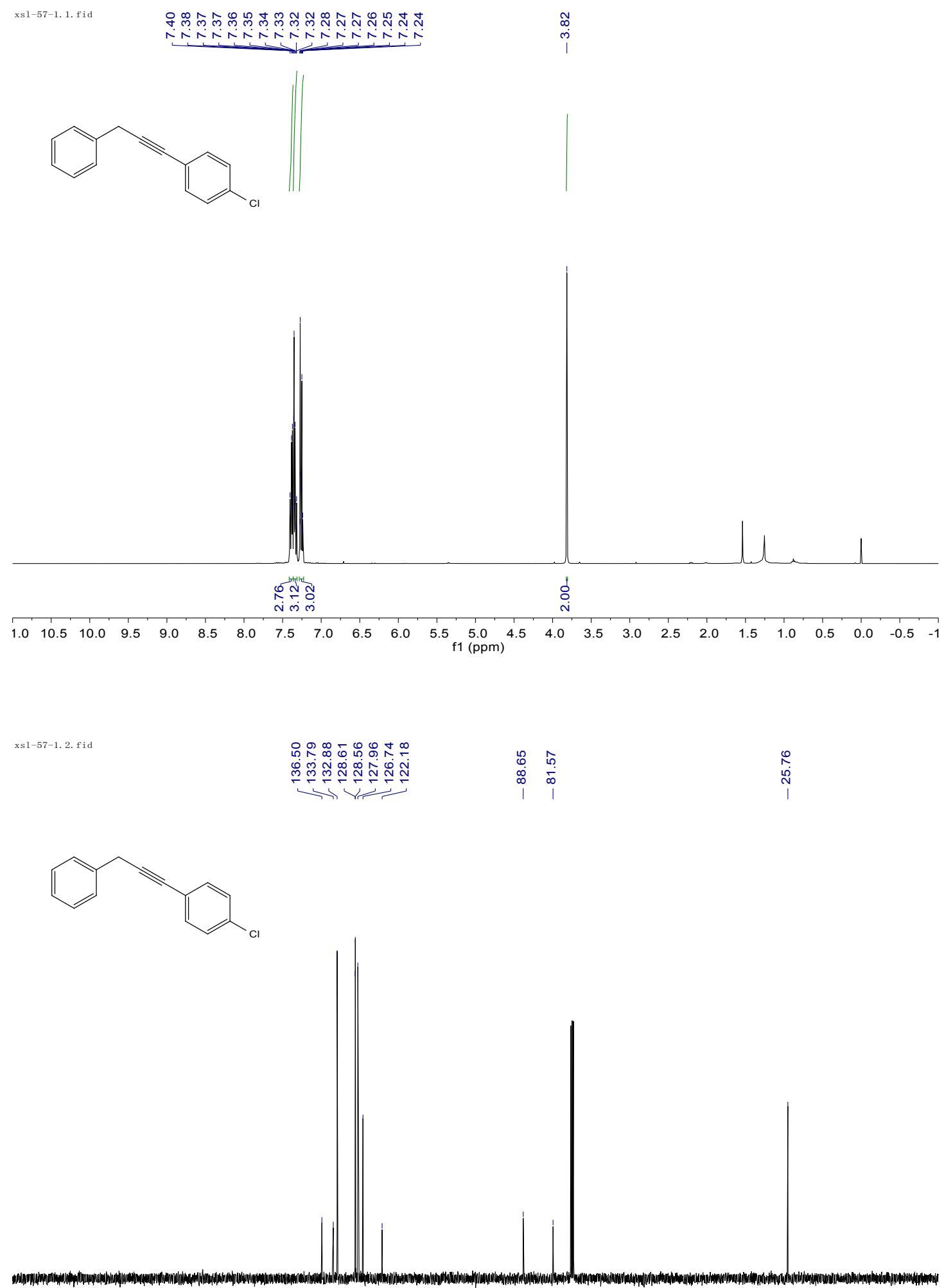

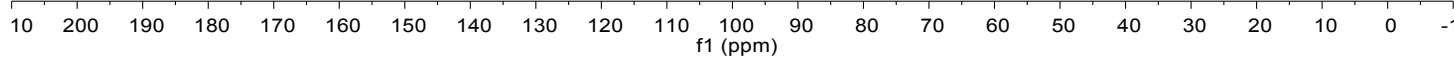

${ }^{1} \mathrm{H}$ NMR and ${ }^{13} \mathrm{C}$ NMR for compound 3ai 


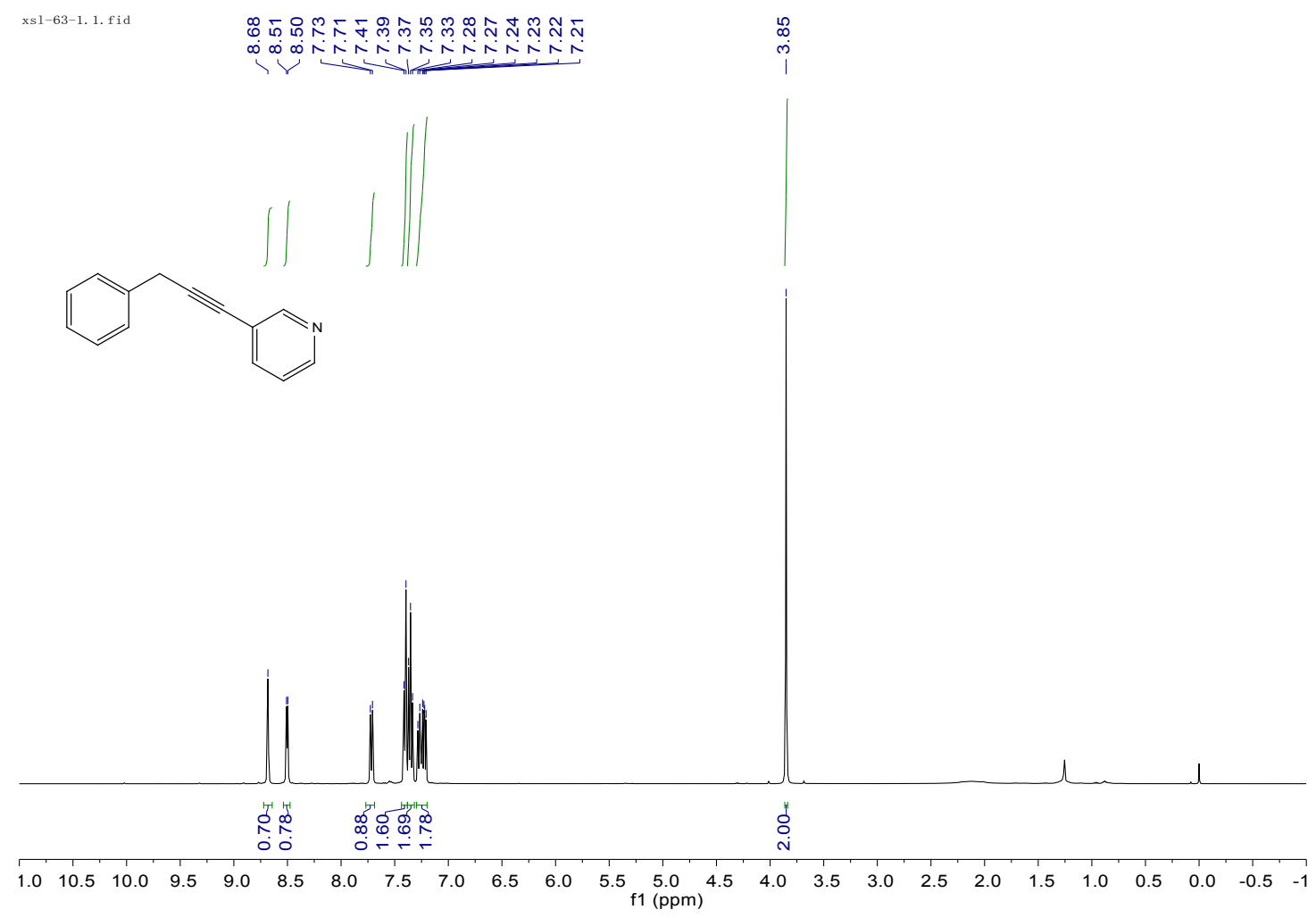

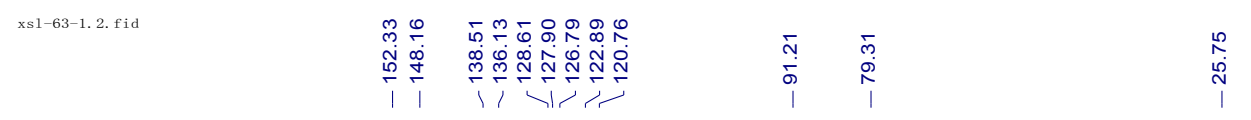

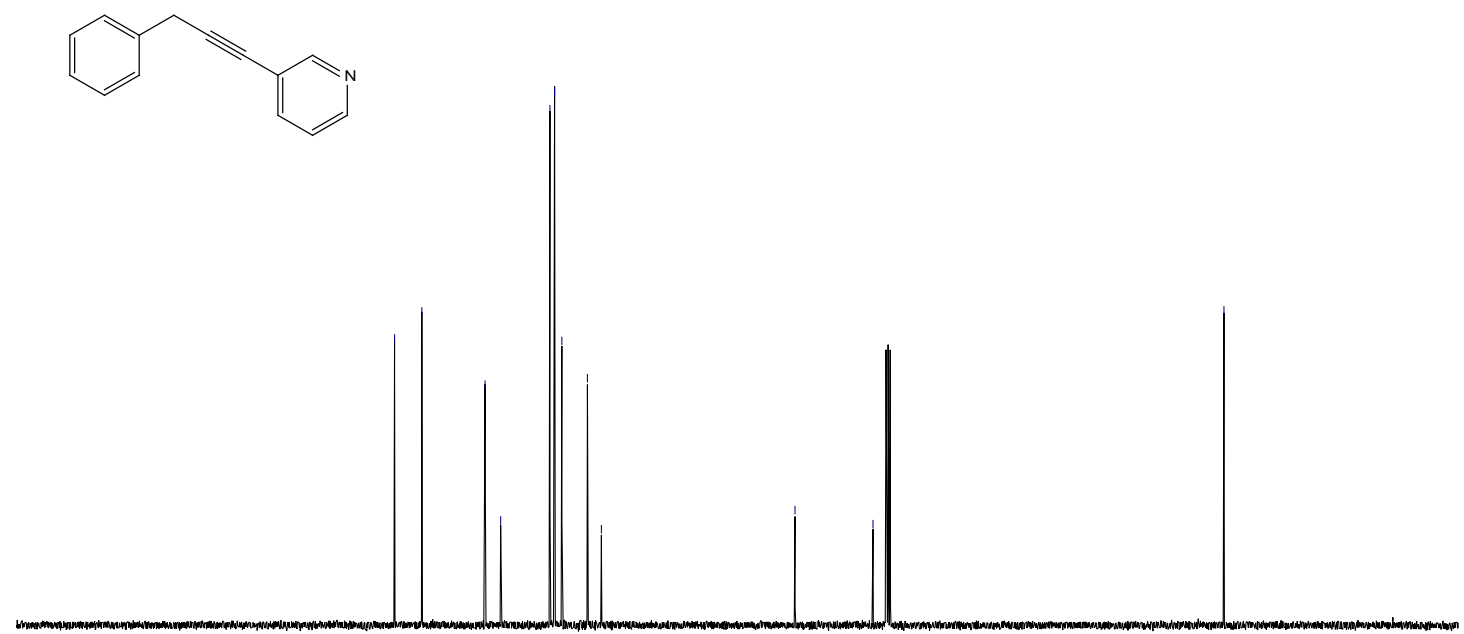

\begin{tabular}{llllllllllllllllllllllllll}
\hline 10 & 200 & 190 & 180 & 170 & 160 & 150 & 140 & 130 & 120 & 110 & 100 & 90 & 80 & 70 & 60 & 50 & 40 & 30 & 20 & 10 & 0 & -
\end{tabular}

${ }^{1} \mathrm{H}$ NMR and ${ }^{13} \mathrm{C}$ NMR for compound $\mathbf{3 a j}$ 

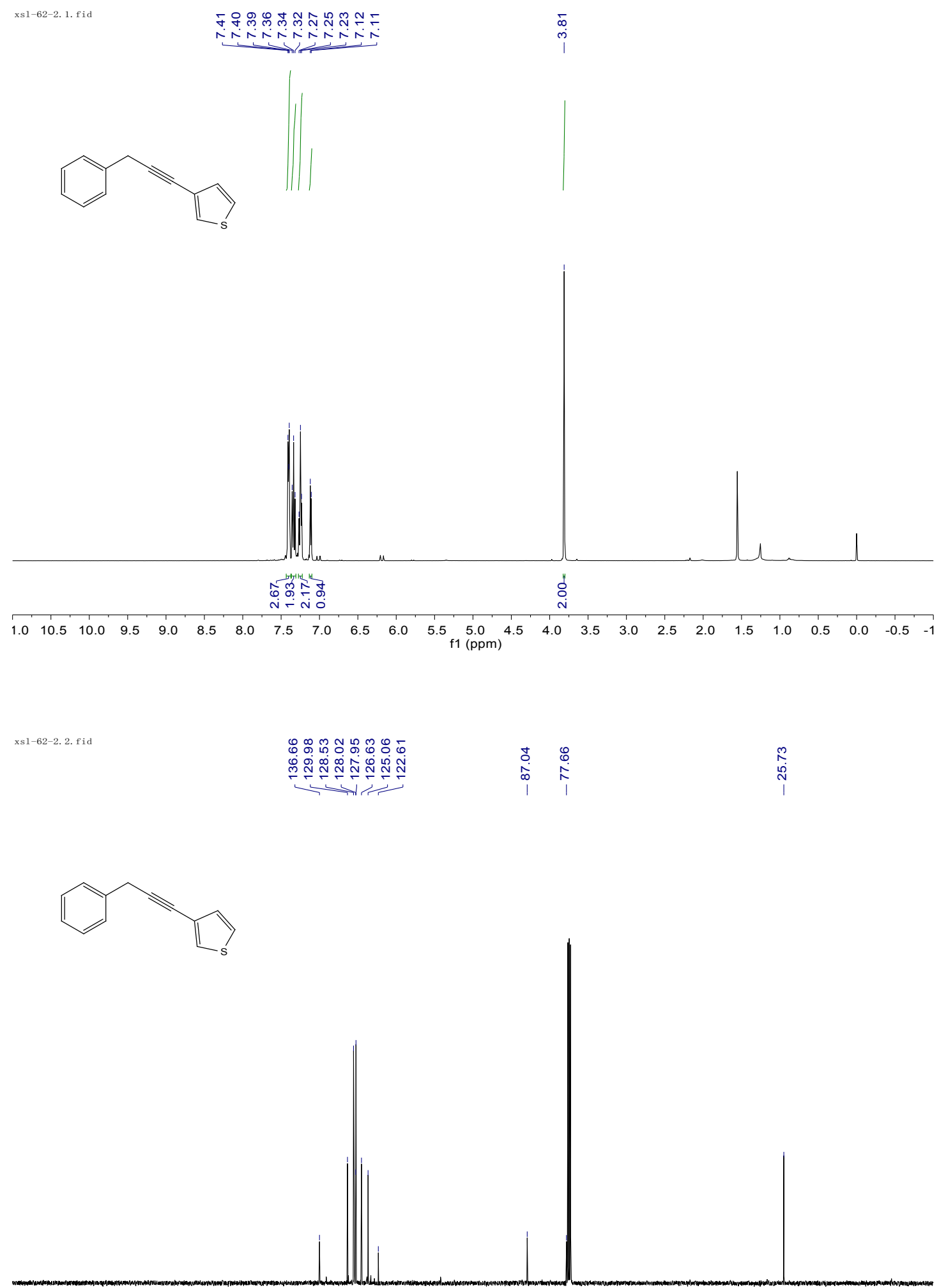

\begin{tabular}{llllllllllllllllllllllllll}
\hline 10 & 200 & 190 & 180 & 170 & 160 & 150 & 140 & 130 & 120 & 110 & 100 & 90 & 80 & 70 & 60 & 50 & 40 & 30 & 20 & 10 & 0 & -
\end{tabular}

${ }^{1} \mathrm{H}$ NMR and ${ }^{13} \mathrm{C}$ NMR for compound $\mathbf{3 a k}$ 


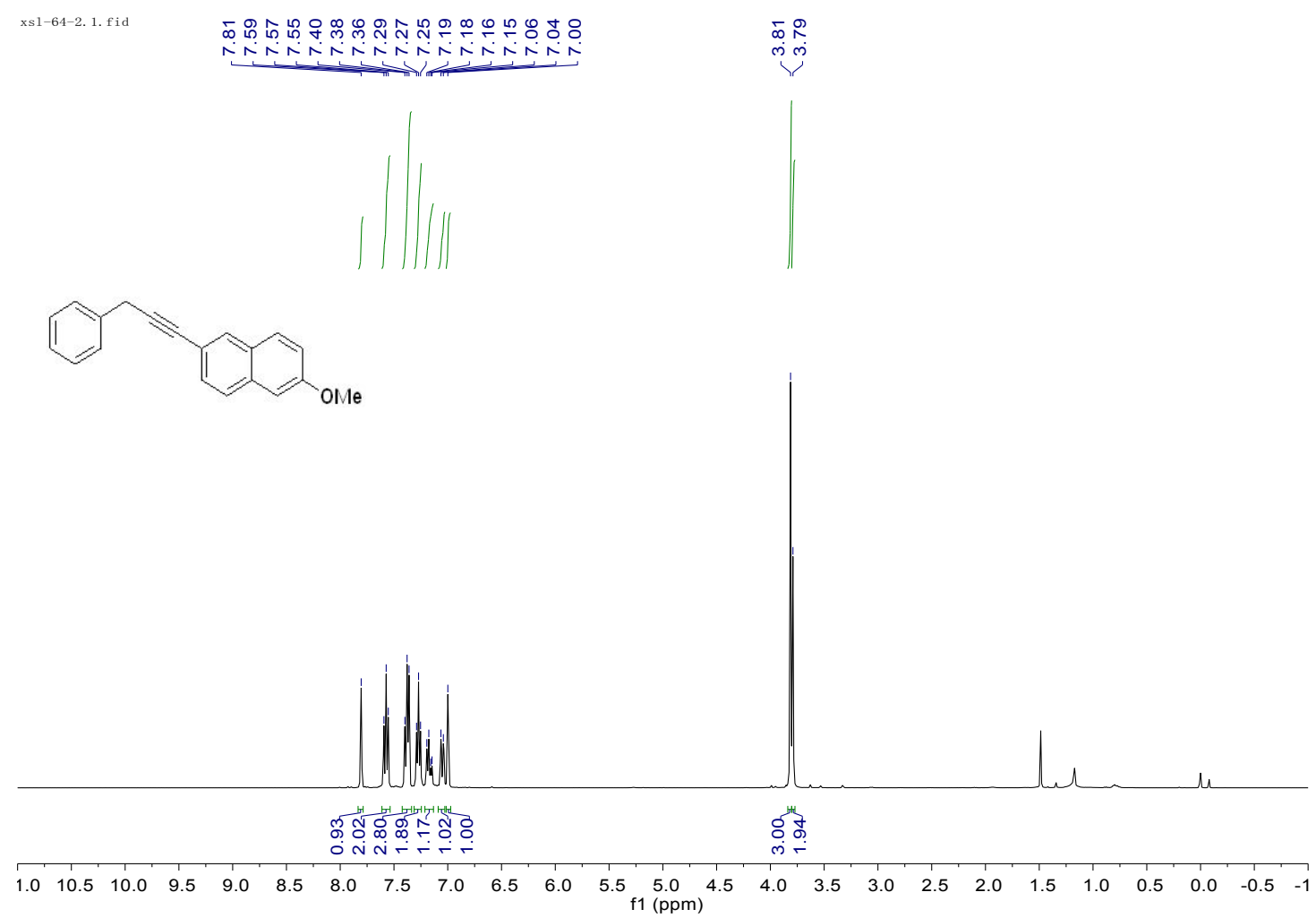

xs1-64-2.2.fid

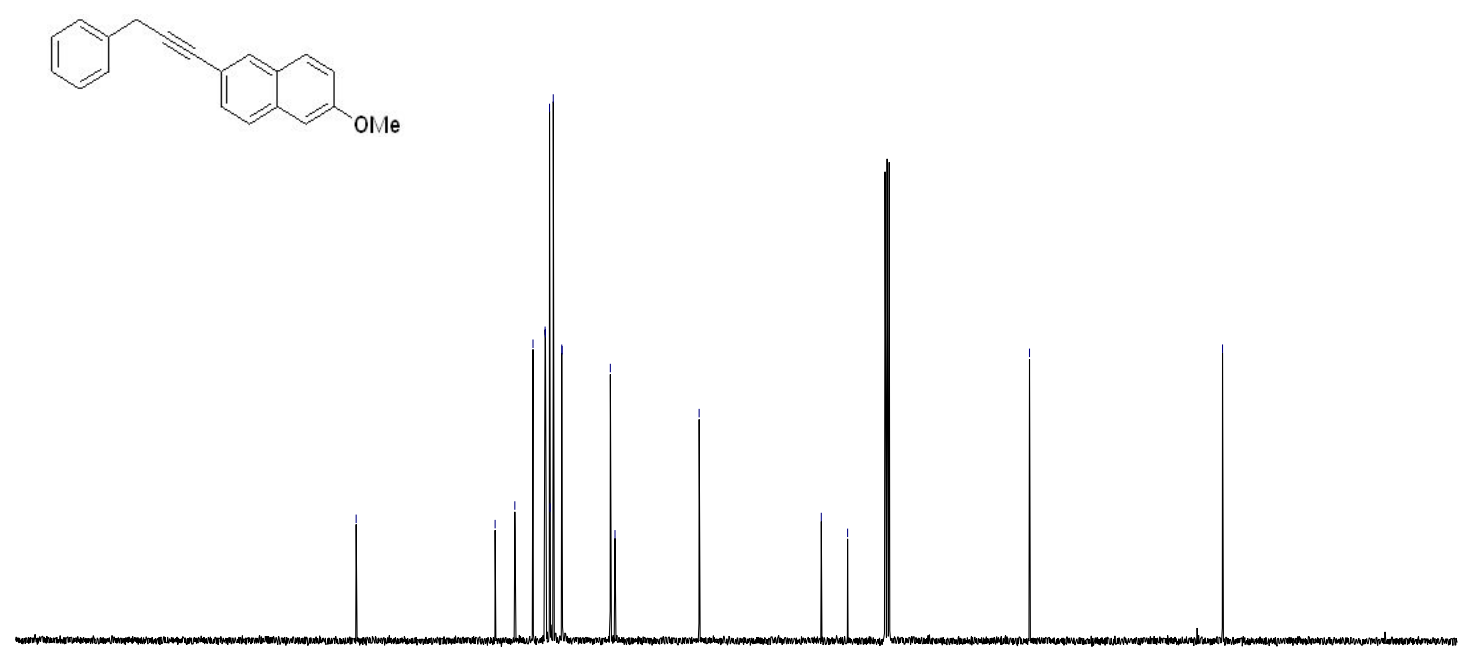

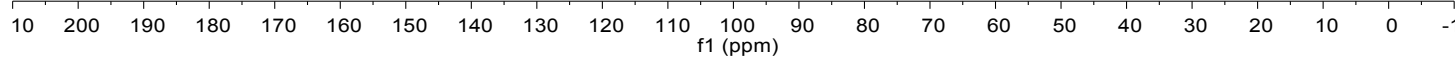

${ }^{1} \mathrm{H}$ NMR and ${ }^{13} \mathrm{C}$ NMR for compound 3al 

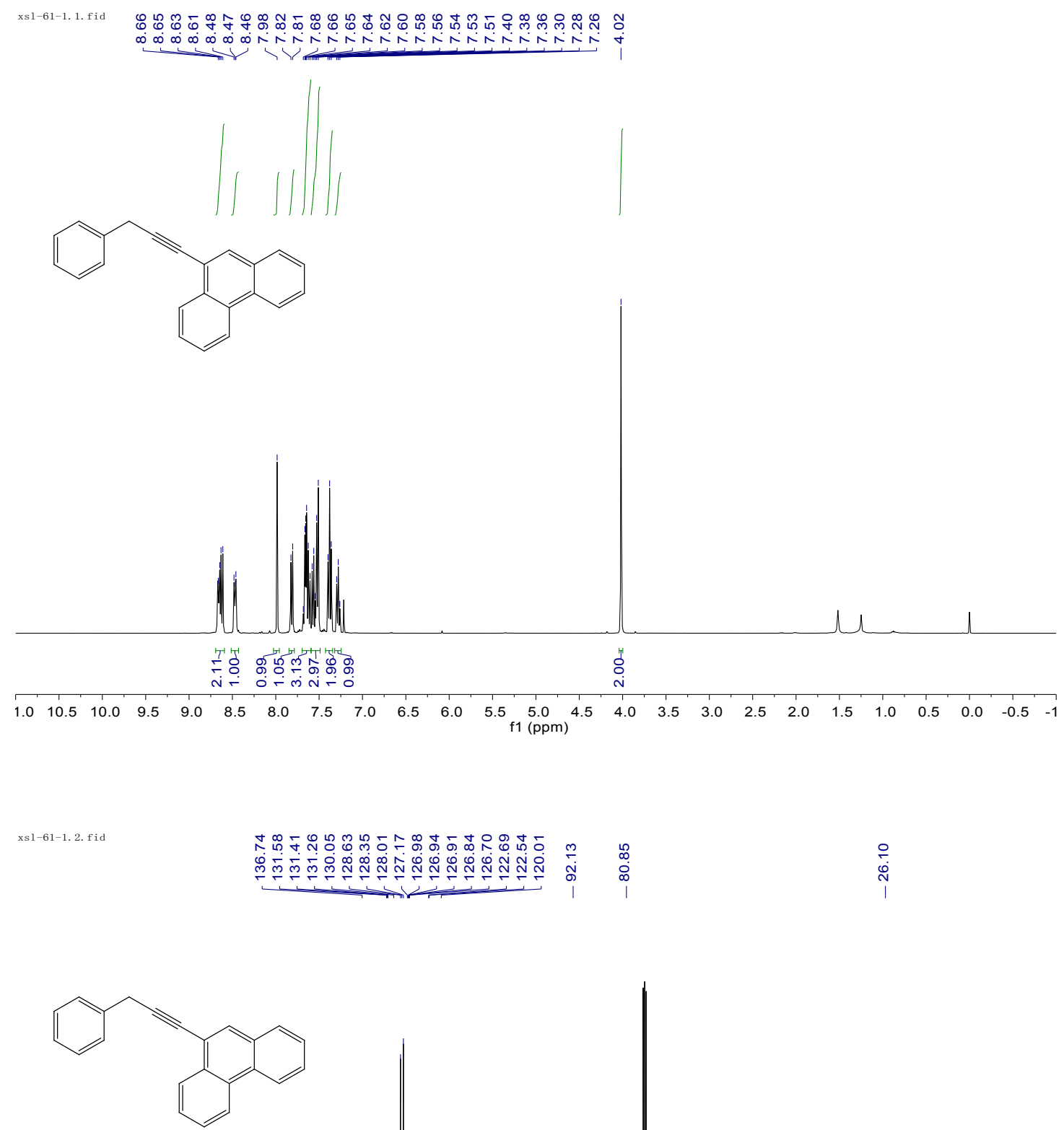

$\begin{array}{lllllllllll}10 & 200 & 190 & 180 & 170 & 160 & 150 & 140 & 130 & 120 & 110 \begin{array}{c}100 \\ \mathrm{f} 1(\mathrm{ppm})\end{array}\end{array}$

${ }^{1} \mathrm{H}$ NMR and ${ }^{13} \mathrm{C}$ NMR for compound 3am 

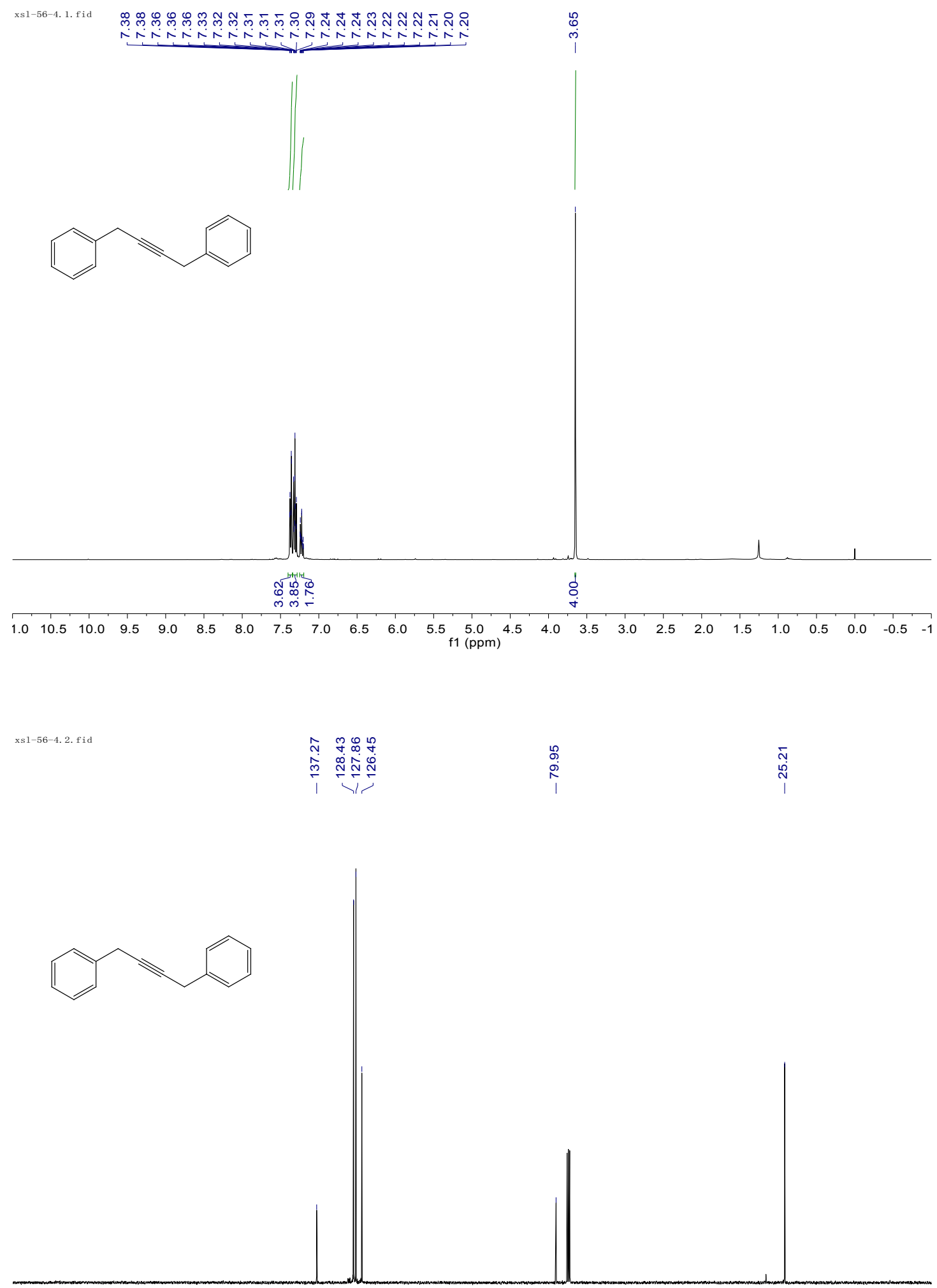

$\begin{array}{lllllllllllllllllllllllllllllll}10 & 200 & 190 & 180 & 170 & 160 & 150 & 140 & 130 & 120 & 110 & 100 & 90 & 80 & 70 & 60 & 50 & 40 & 30 & 20 & 10 & 0 & -\end{array}$

${ }^{1} \mathrm{H}$ NMR and ${ }^{13} \mathrm{C}$ NMR for compound 3an 


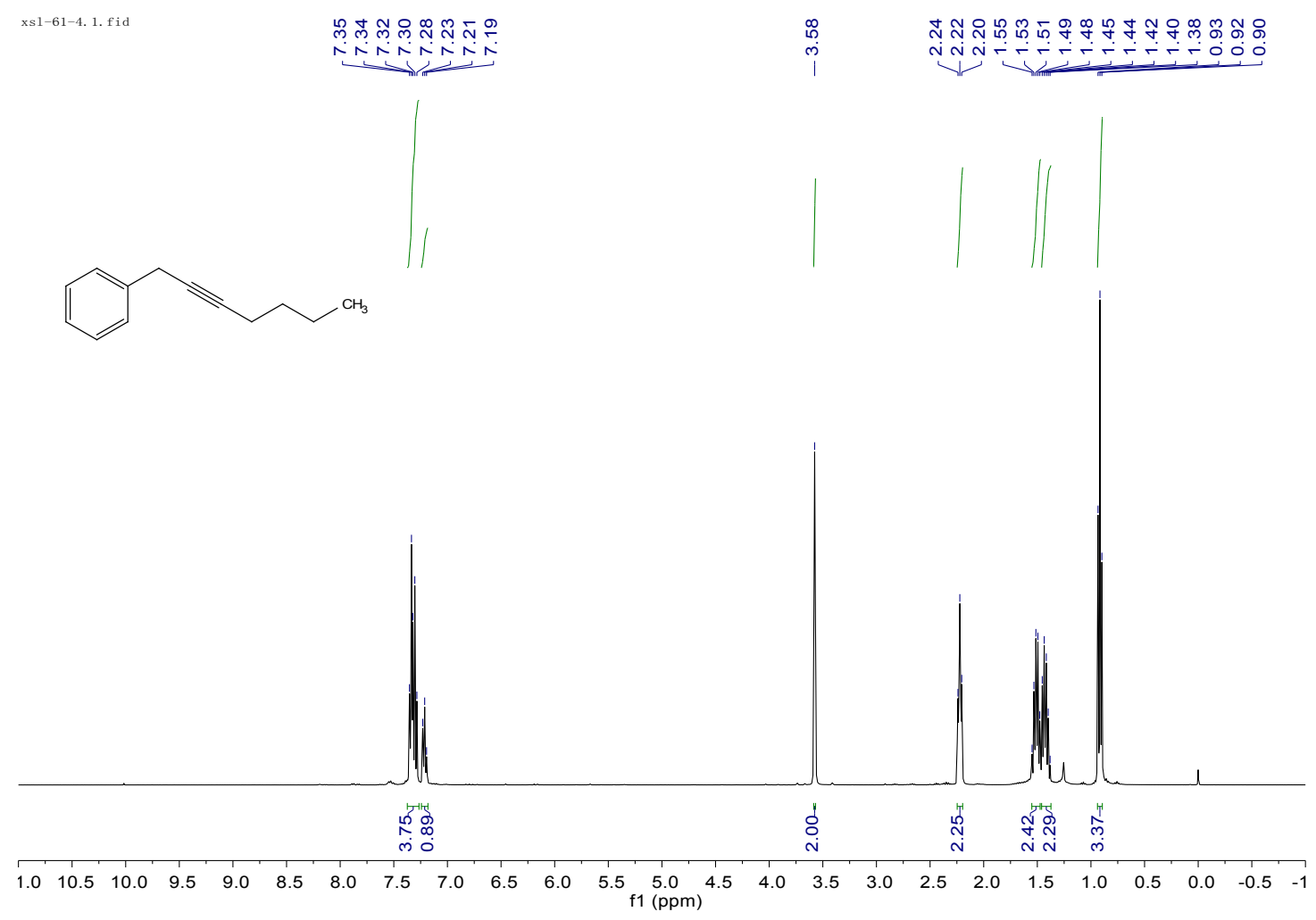

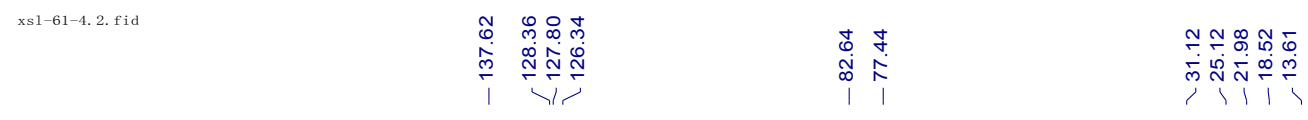

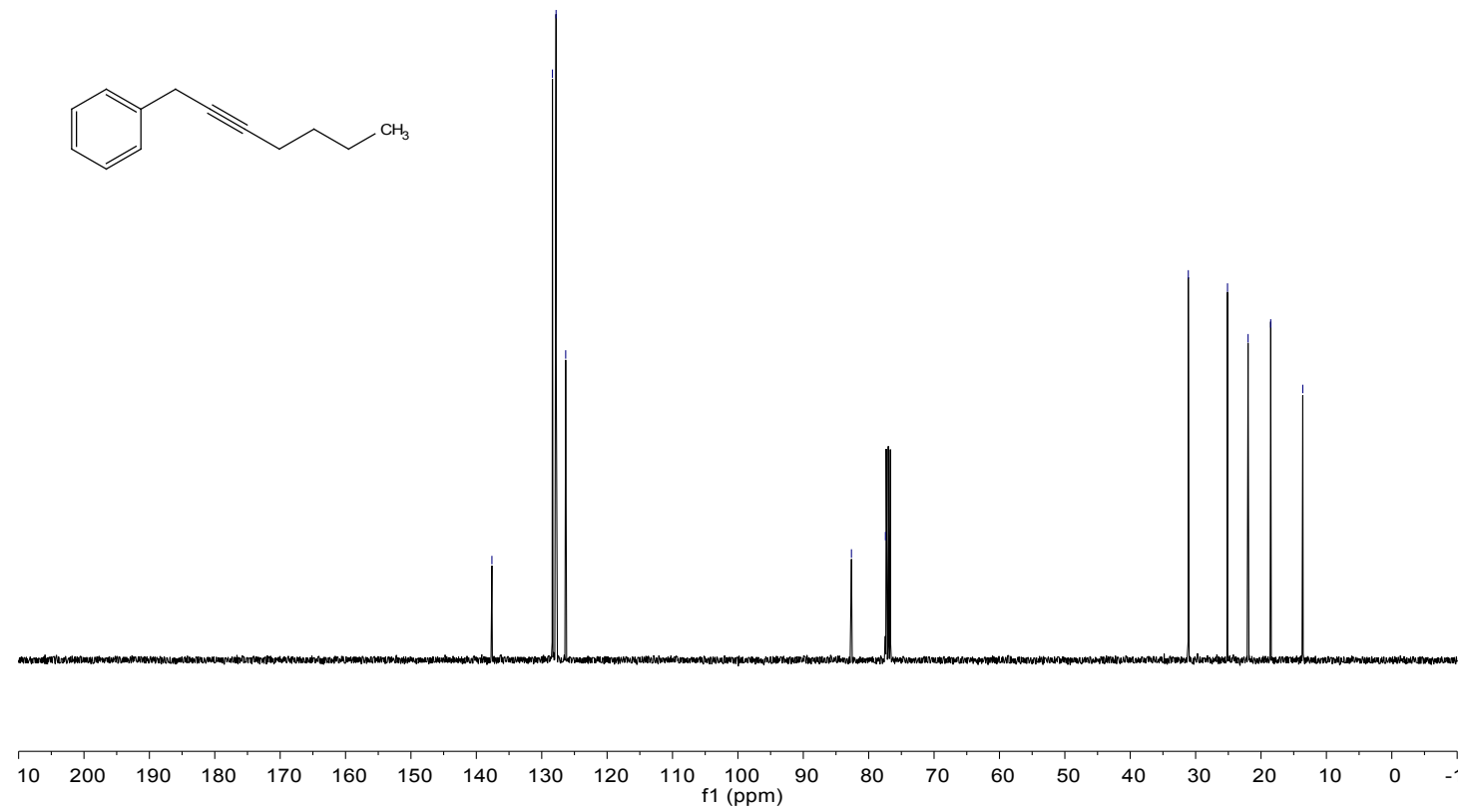

${ }^{1} \mathrm{H}$ NMR and ${ }^{13} \mathrm{C}$ NMR for compound 3ao 


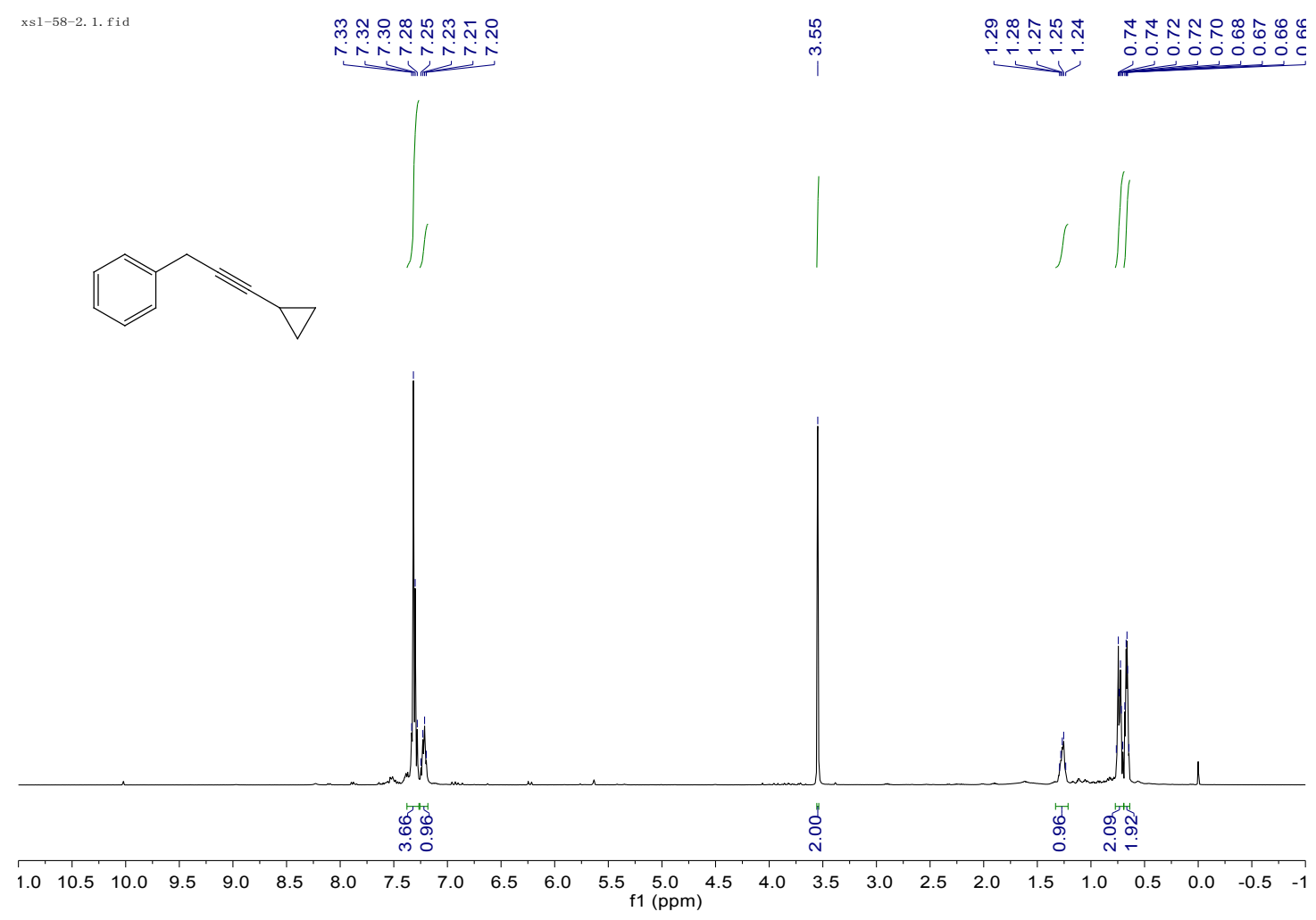

xs1-58-2.2. fid

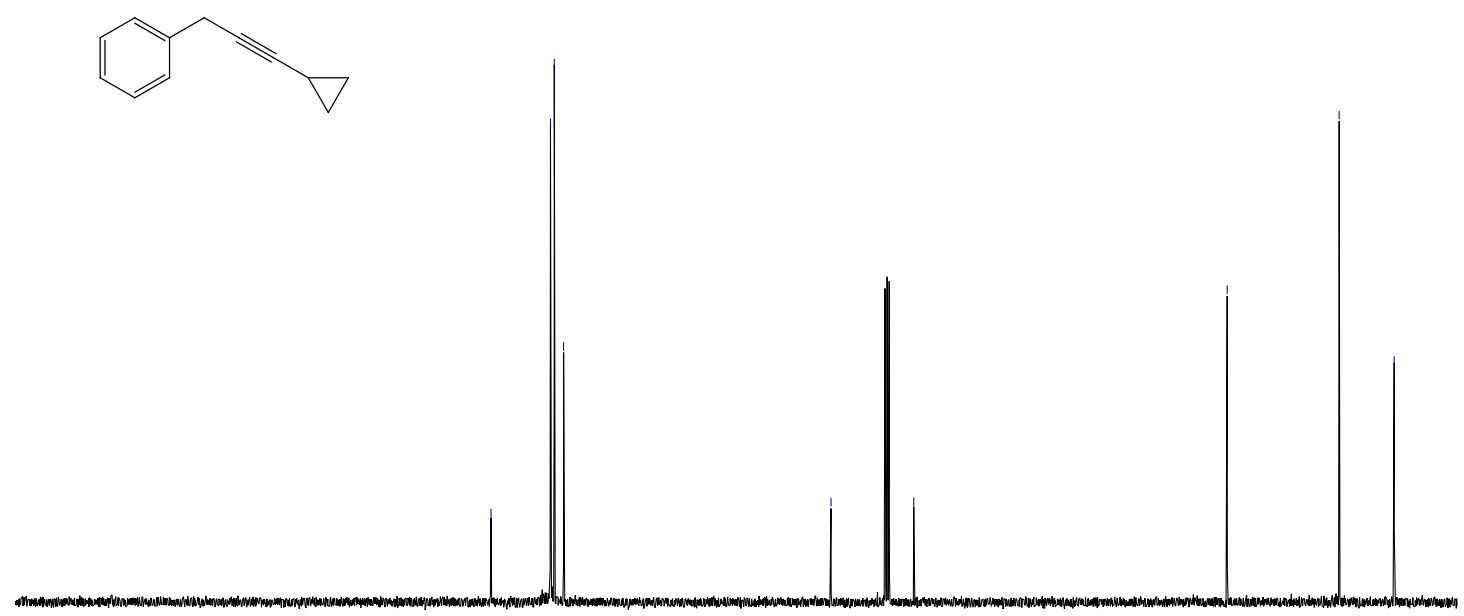

$\begin{array}{lllllllllllllllllllllllll}10 & 200 & 190 & 180 & 170 & 160 & 150 & 140 & 130 & 120 & 110 & 100 & 90 & 80 & 70 & 60 & 50 & 40 & 30 & 20 & 10 & 0 & -\end{array}$

${ }^{1} \mathrm{H}$ NMR and ${ }^{13} \mathrm{C}$ NMR for compound 3ap 

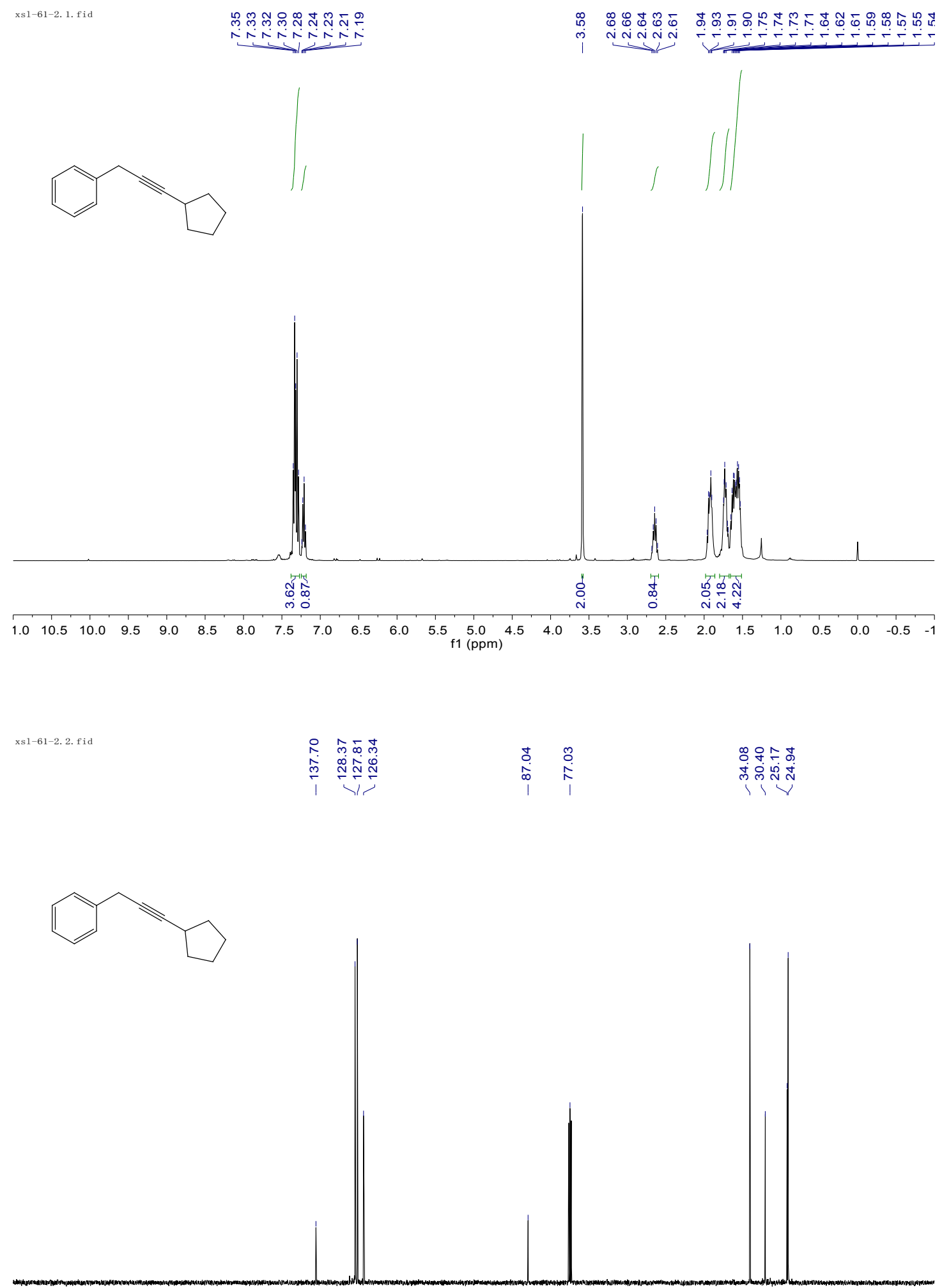

$\begin{array}{lllllllllllllllllllllllllllll}10 & 200 & 190 & 180 & 170 & 160 & 150 & 140 & 130 & 120 & 110 & 100 & 90 & 80 & 70 & 60 & 50 & 40 & 30 & 20 & 10 & 0 & -\end{array}$

${ }^{1} \mathrm{H}$ NMR and ${ }^{13} \mathrm{C}$ NMR for compound $\mathbf{3 a q}$ 

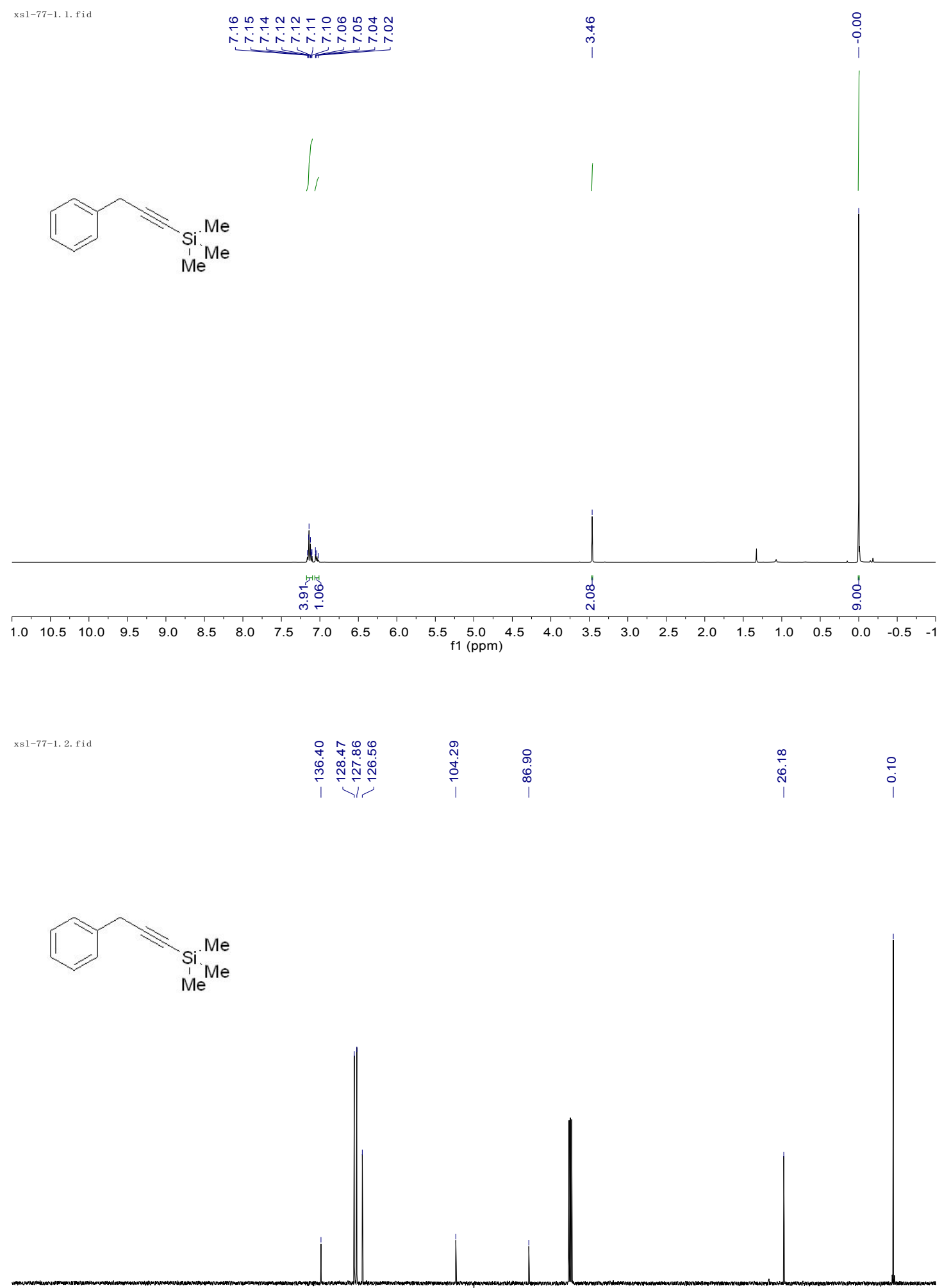

\begin{tabular}{lllllllllllllllllllllllll}
\hline 10 & 200 & 190 & 180 & 170 & 160 & 150 & 140 & 130 & 120 & 110 & 100 & 90 & 80 & 70 & 60 & 50 & 40 & 30 & 20 & 10 & 0 & -
\end{tabular}

${ }^{1} \mathrm{H}$ NMR and ${ }^{13} \mathrm{C}$ NMR for compound 3ar 


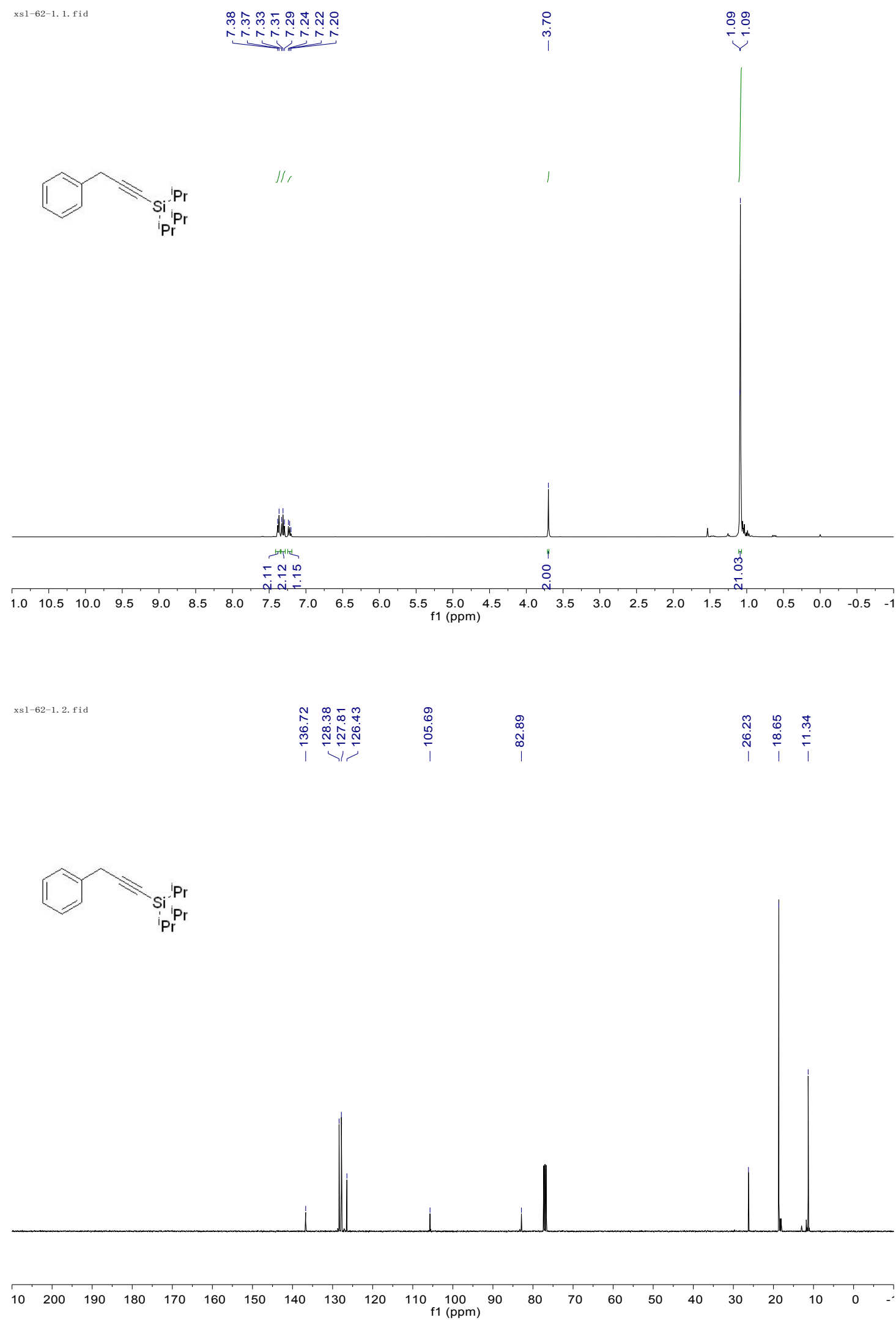

${ }^{1} \mathrm{H}$ NMR and ${ }^{13} \mathrm{C}$ NMR for compound 3as 


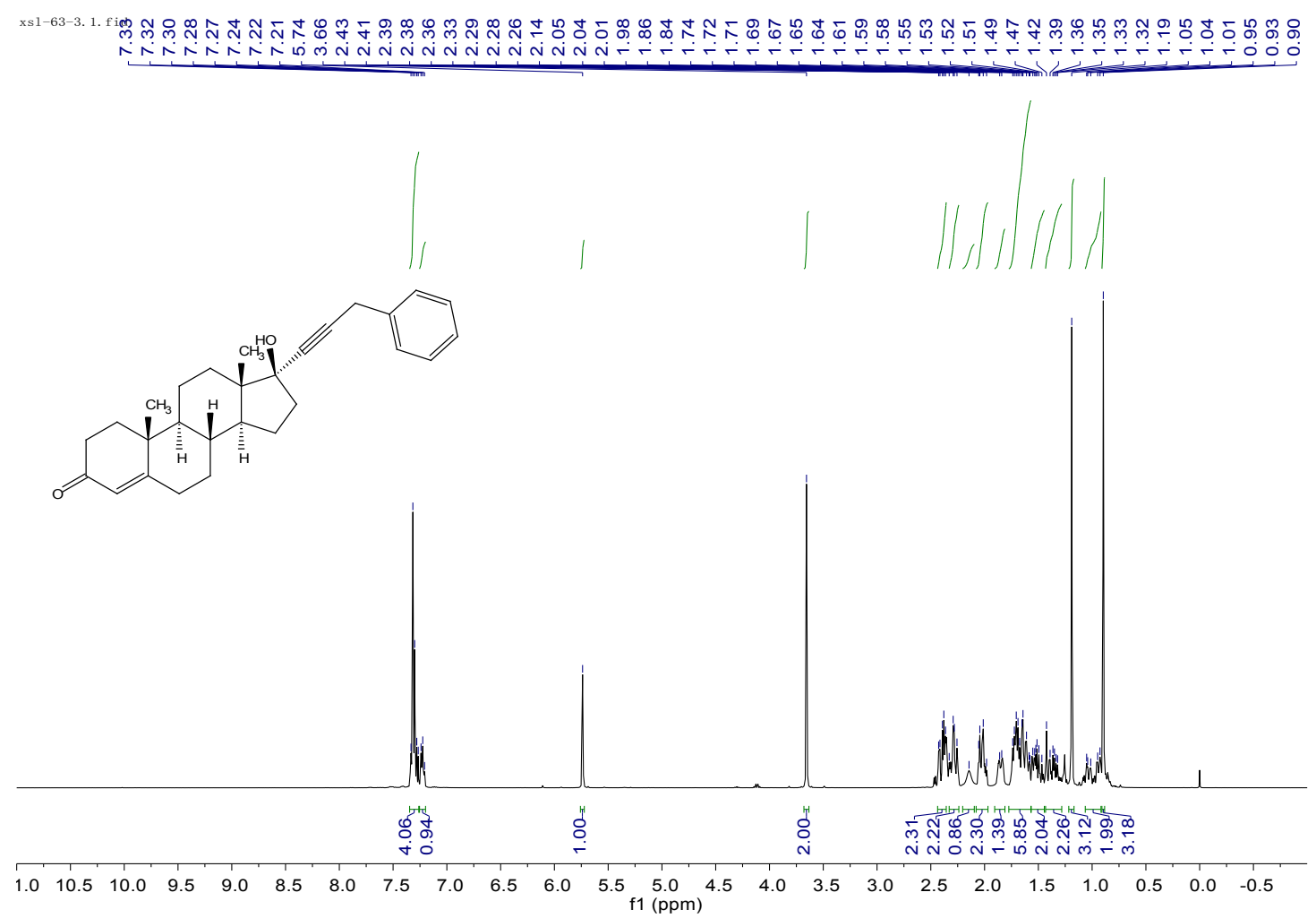

\begin{tabular}{|c|c|c|c|c|}
\hline xsl-63 th. 2.fid & $\begin{array}{l}\stackrel{0}{N} \\
\stackrel{N}{\leftarrow} \\
i\end{array}$ & 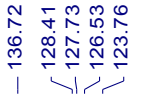 & 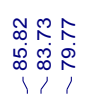 & 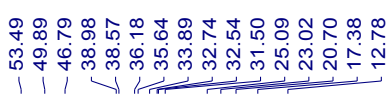 \\
\hline
\end{tabular}

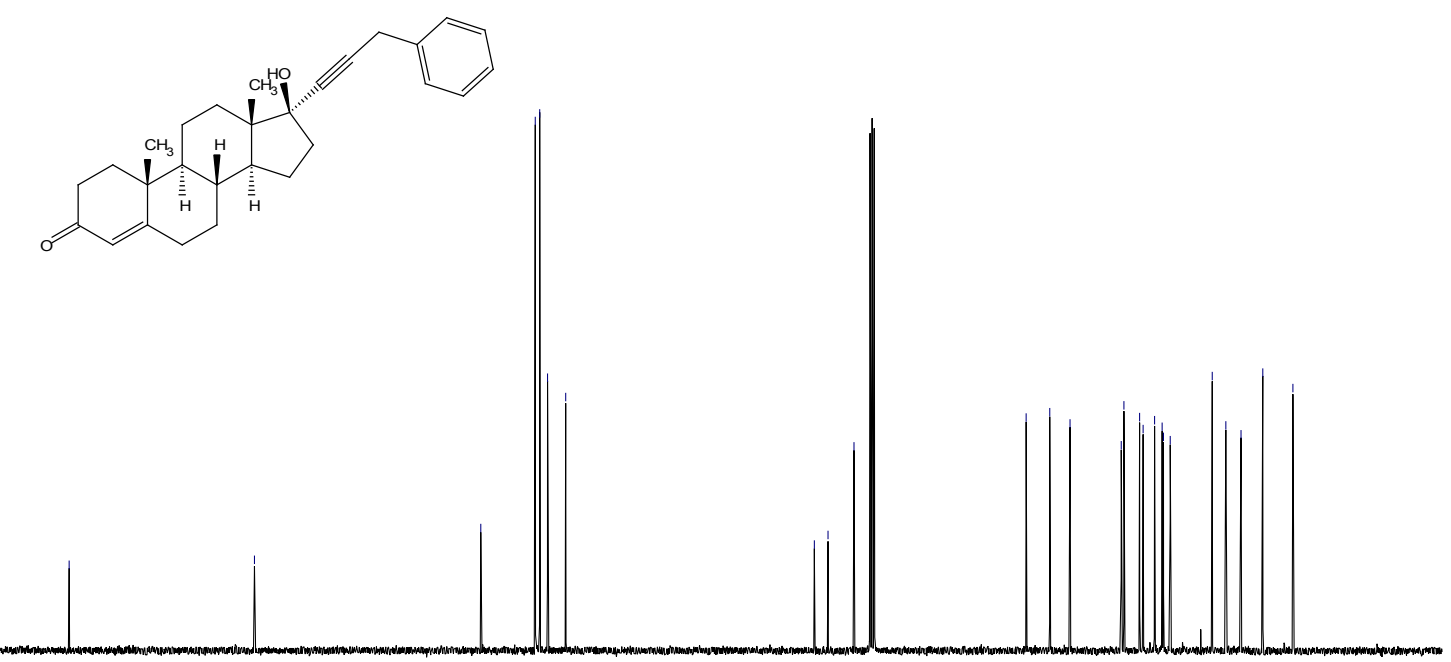

\begin{tabular}{llllllllllllllllllllllll}
\hline 10 & 200 & 190 & 180 & 170 & 160 & 150 & 140 & 130 & 120 & 110 & 100 & 90 & 80 & 70 & 60 & 50 & 40 & 30 & 20 & 10 & 0 & -
\end{tabular}

${ }^{1} \mathrm{H}$ NMR and ${ }^{13} \mathrm{C}$ NMR for compound 3at 

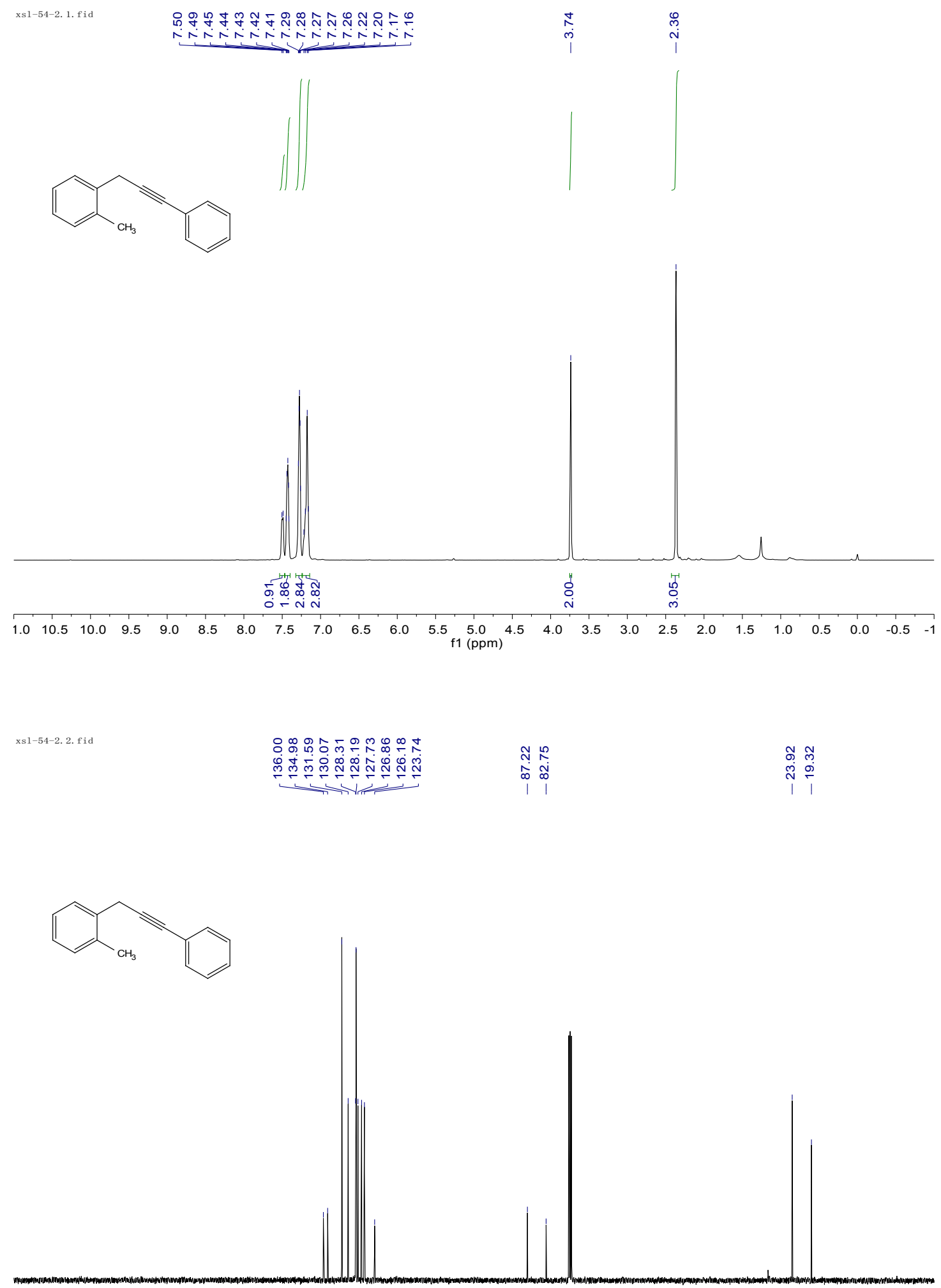

\begin{tabular}{llllllllllllllllllllllllll}
\hline 10 & 200 & 190 & 180 & 170 & 160 & 150 & 140 & 130 & 120 & 110 & 100 & 90 & 80 & 70 & 60 & 50 & 40 & 30 & 20 & 10 & 0 & -
\end{tabular}

${ }^{1} \mathrm{H}$ NMR and ${ }^{13} \mathrm{C}$ NMR for compound 3 ba 


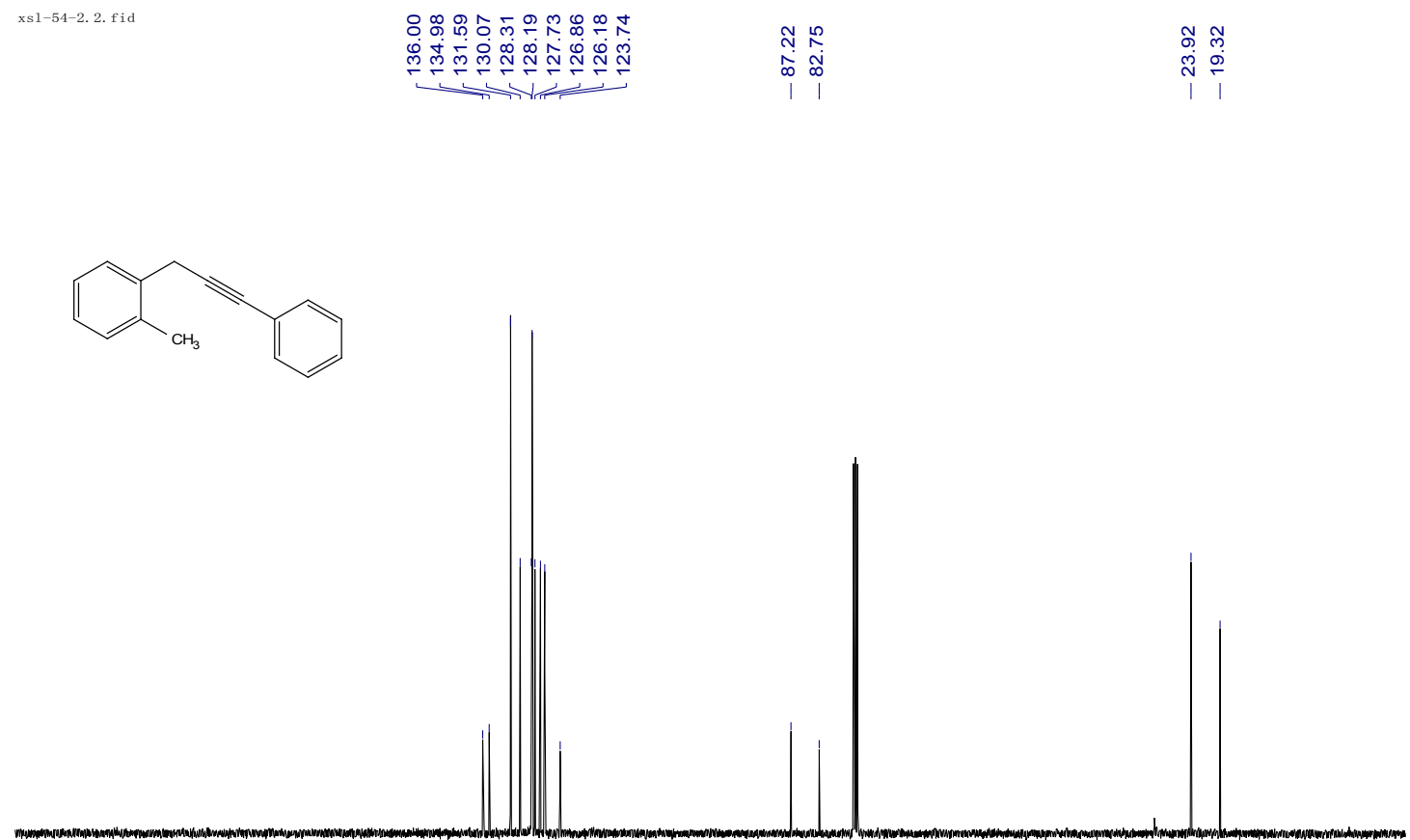

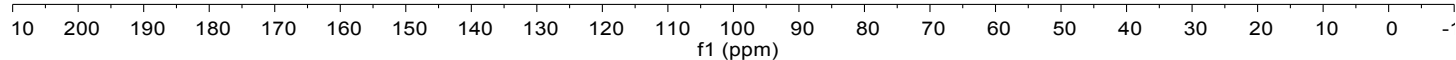

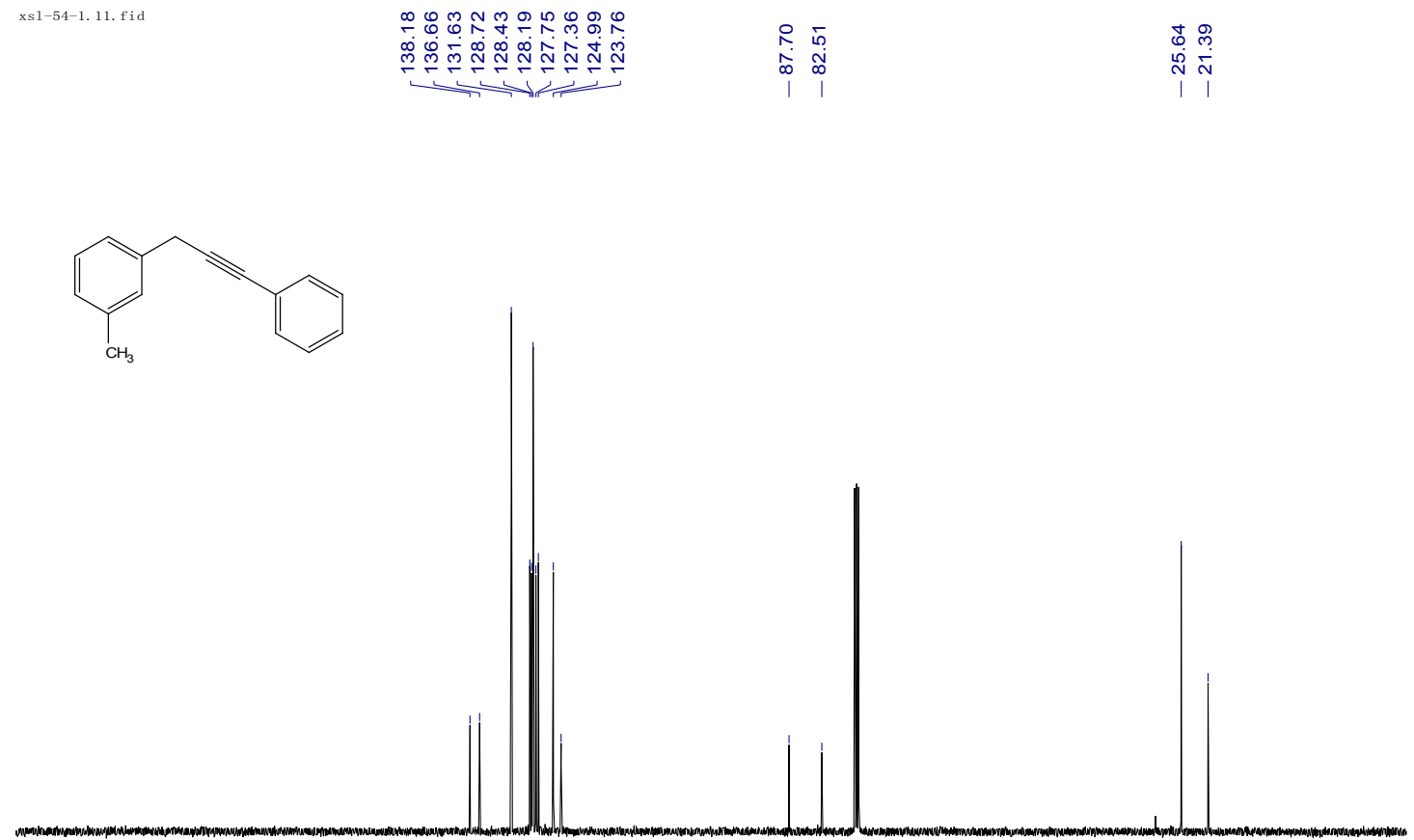

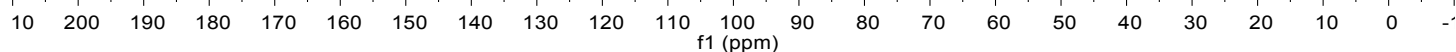

${ }^{1} \mathrm{H}$ NMR and ${ }^{13} \mathrm{C}$ NMR for compound $3 \mathrm{ca}$ 

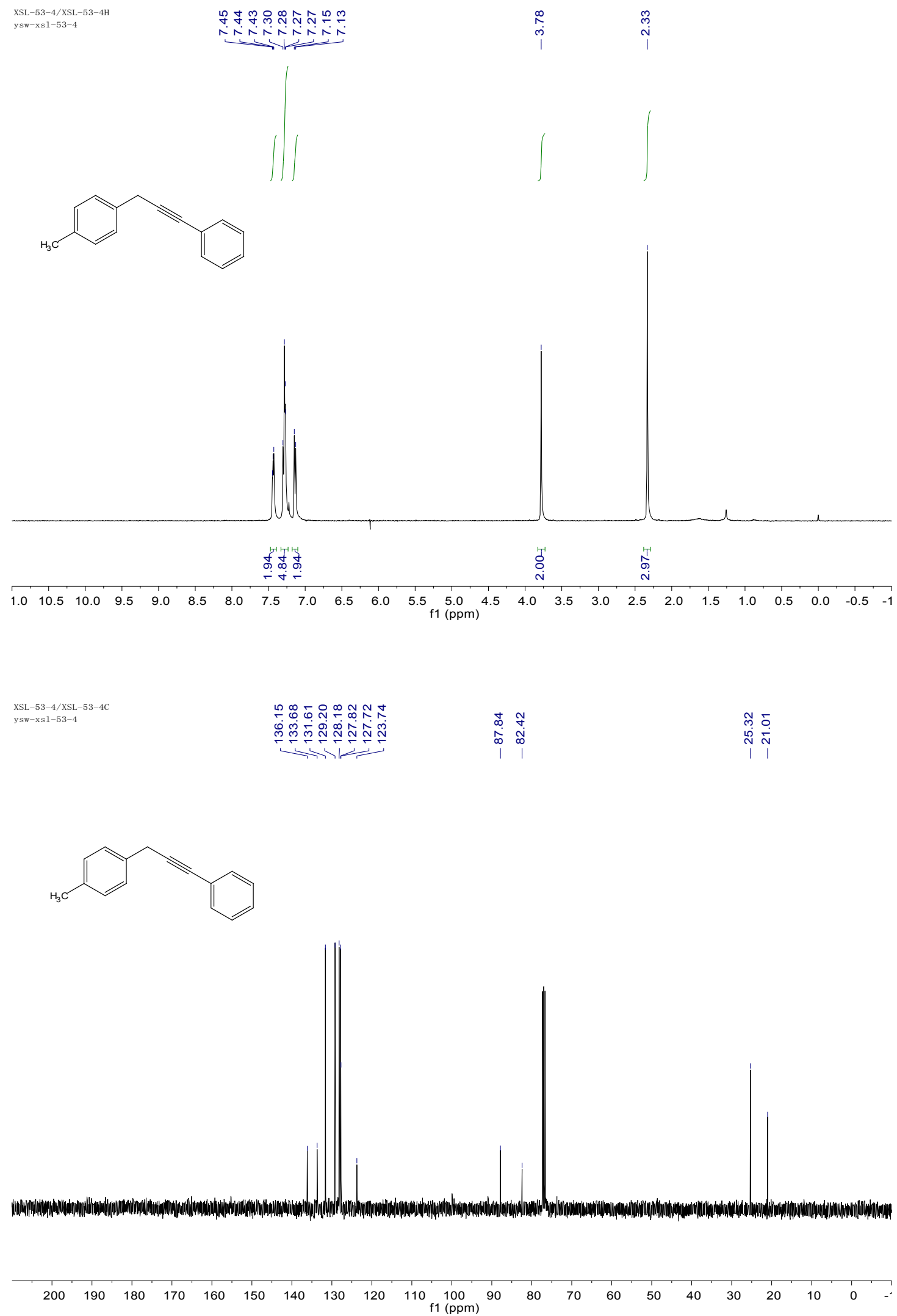

${ }^{1} \mathrm{H}$ NMR and ${ }^{13} \mathrm{C}$ NMR for compound $\mathbf{3 d a}$ 


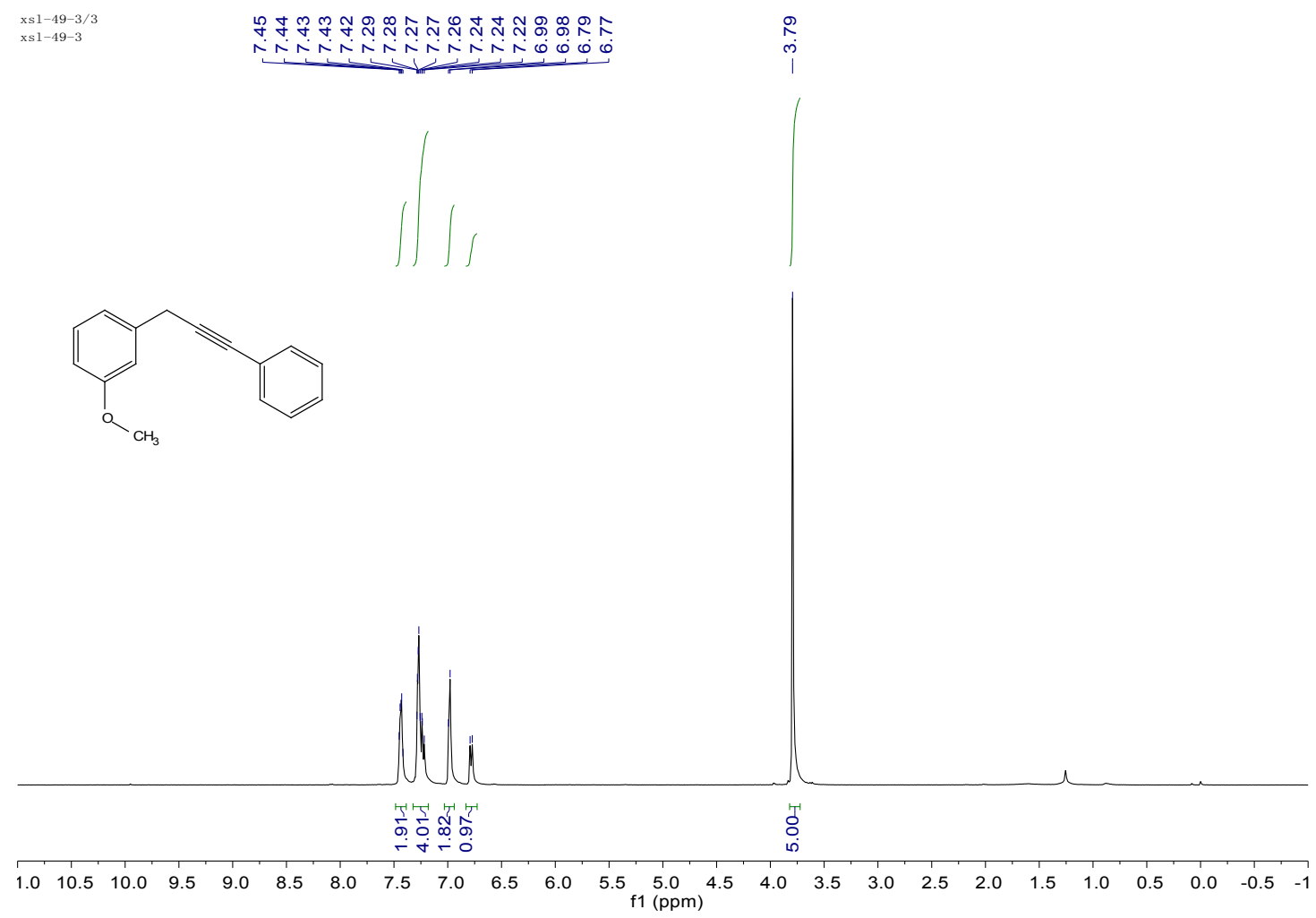

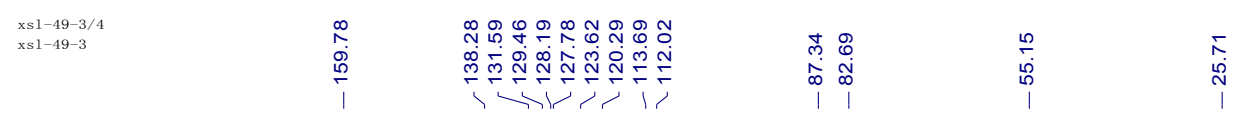

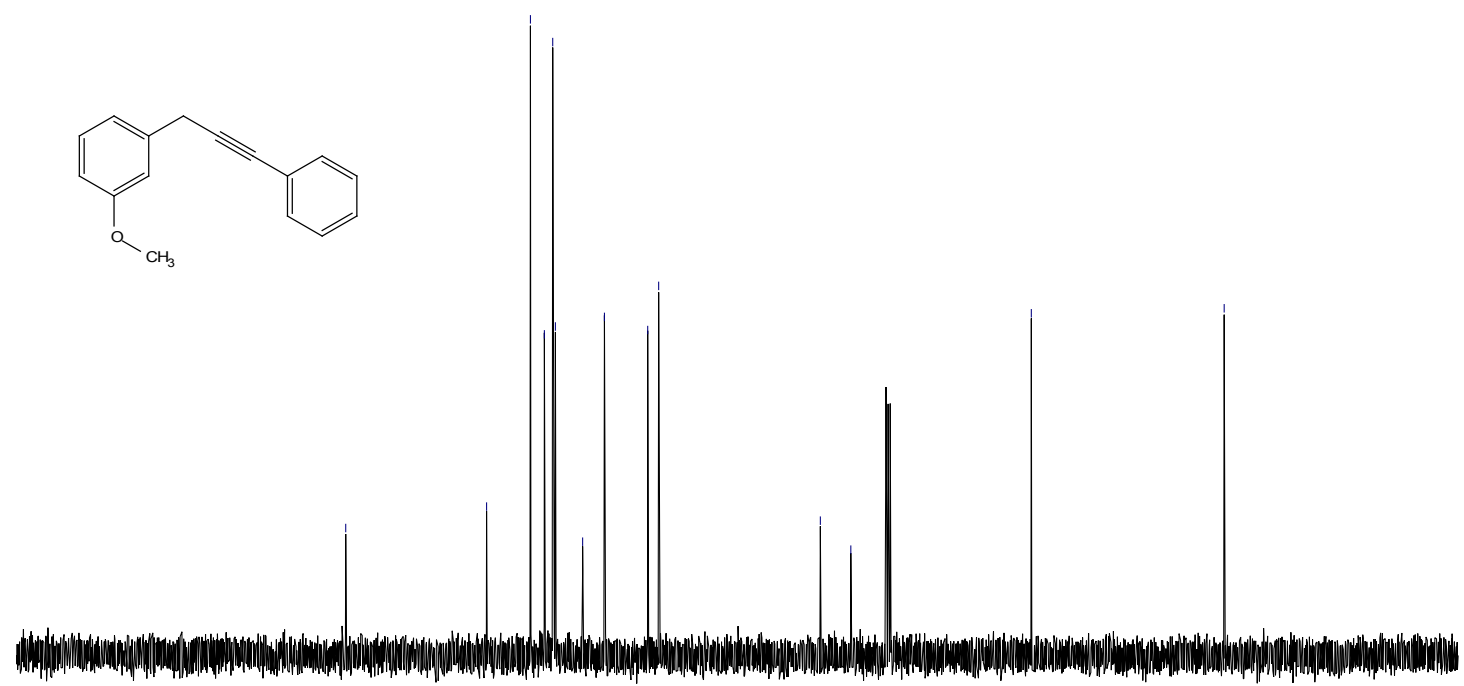

$\begin{array}{lllllllllllllllllllllllllll}200 & 190 & 180 & 170 & 160 & 150 & 140 & 130 & 120 & 110 & 100 & 90 & 80 & 70 & 60 & 50 & 40 & 30 & 20 & 10 & 0 & -\end{array}$

${ }^{1} \mathrm{H}$ NMR and ${ }^{13} \mathrm{C}$ NMR for compound 3ea 


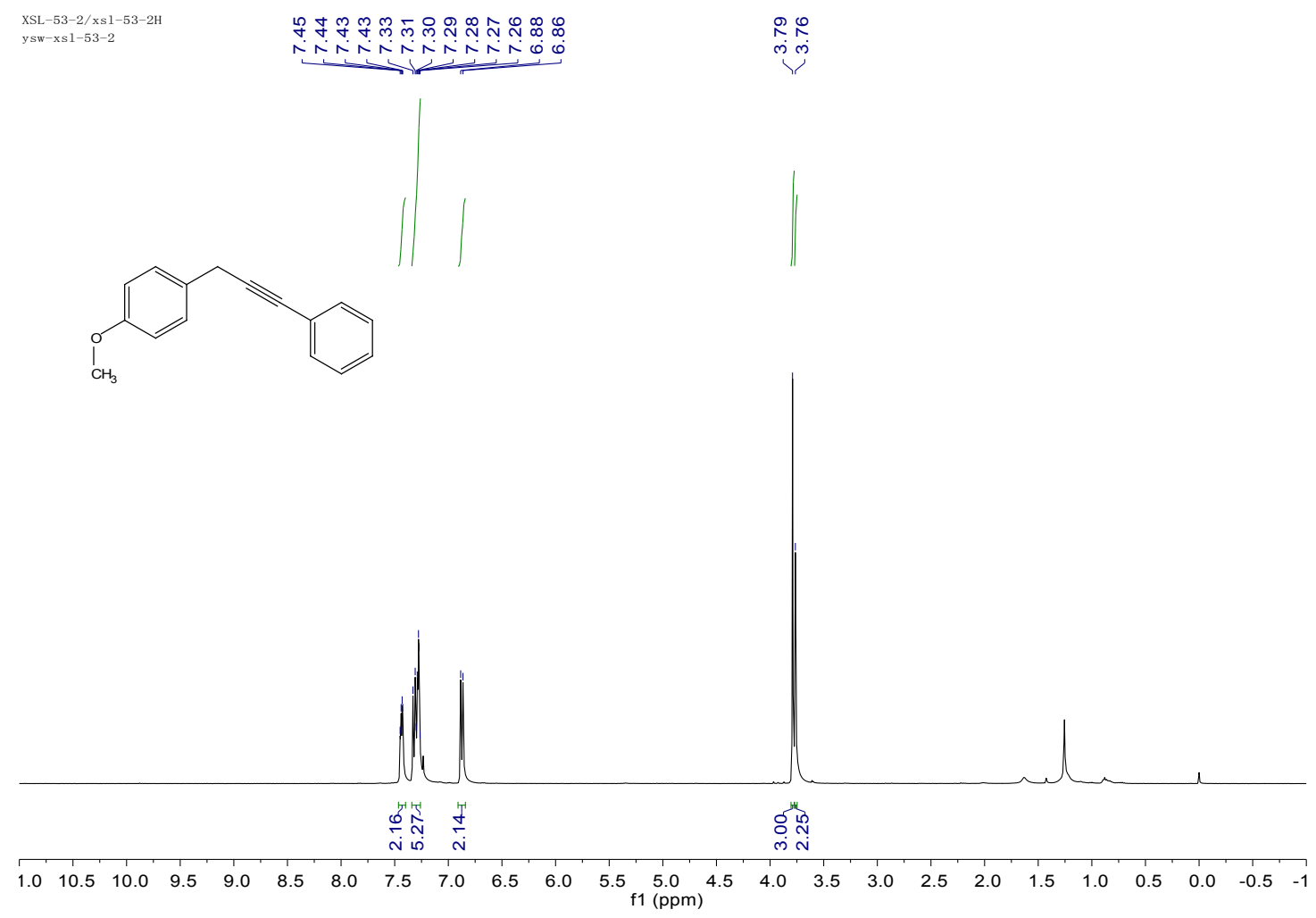

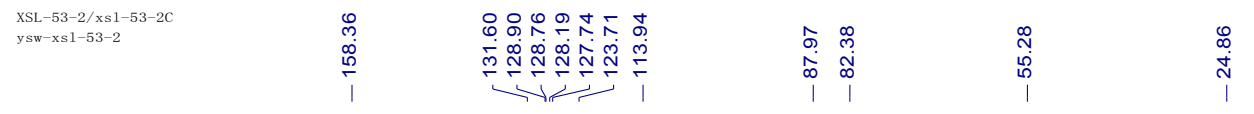

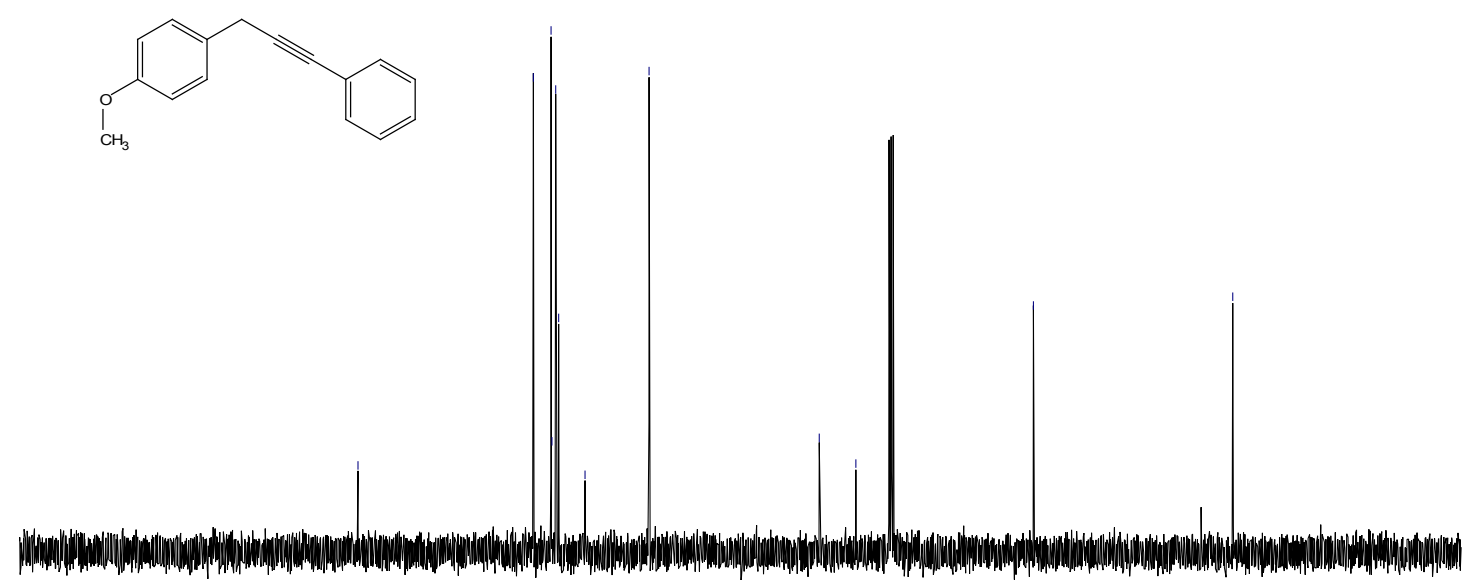

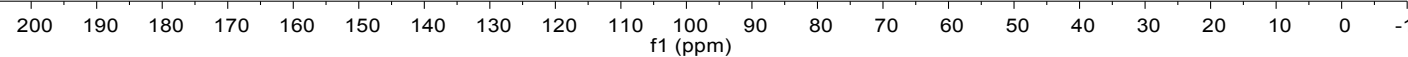

${ }^{1} \mathrm{H}$ NMR and ${ }^{13} \mathrm{C}$ NMR for compound $\mathbf{3 f a}$ 


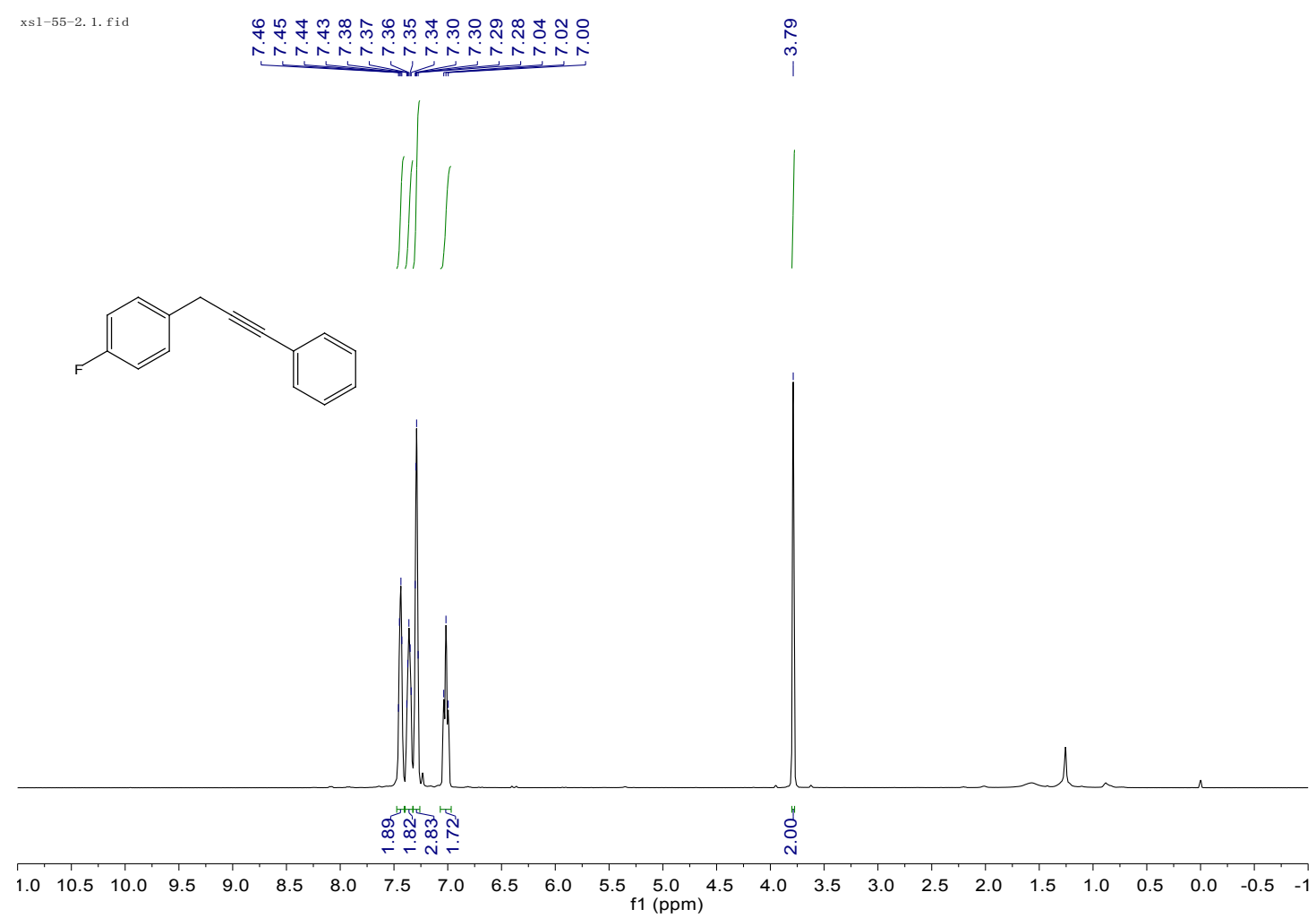

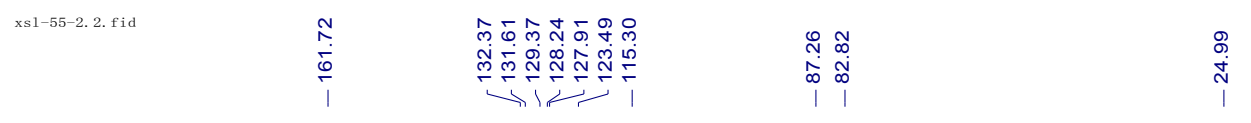

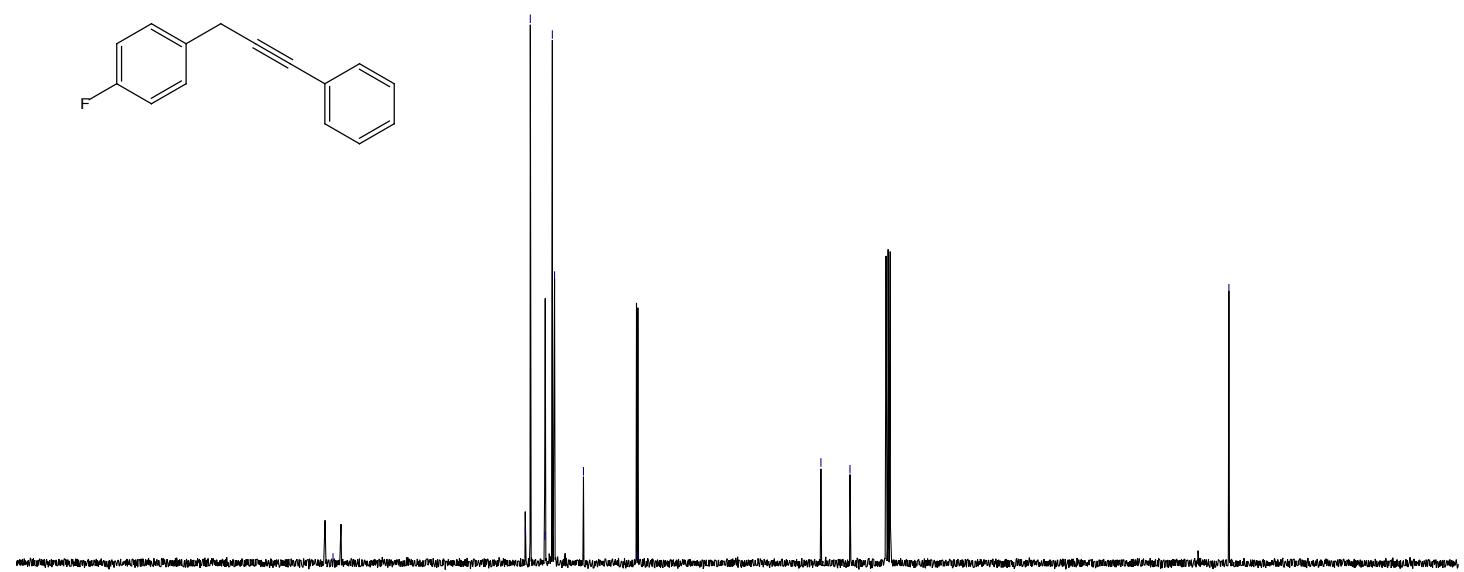

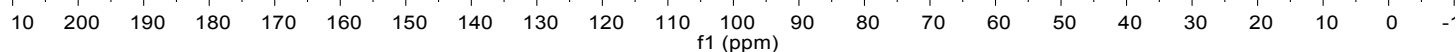

${ }^{1} \mathrm{H}$ NMR and ${ }^{13} \mathrm{C}$ NMR for compound 3ga 

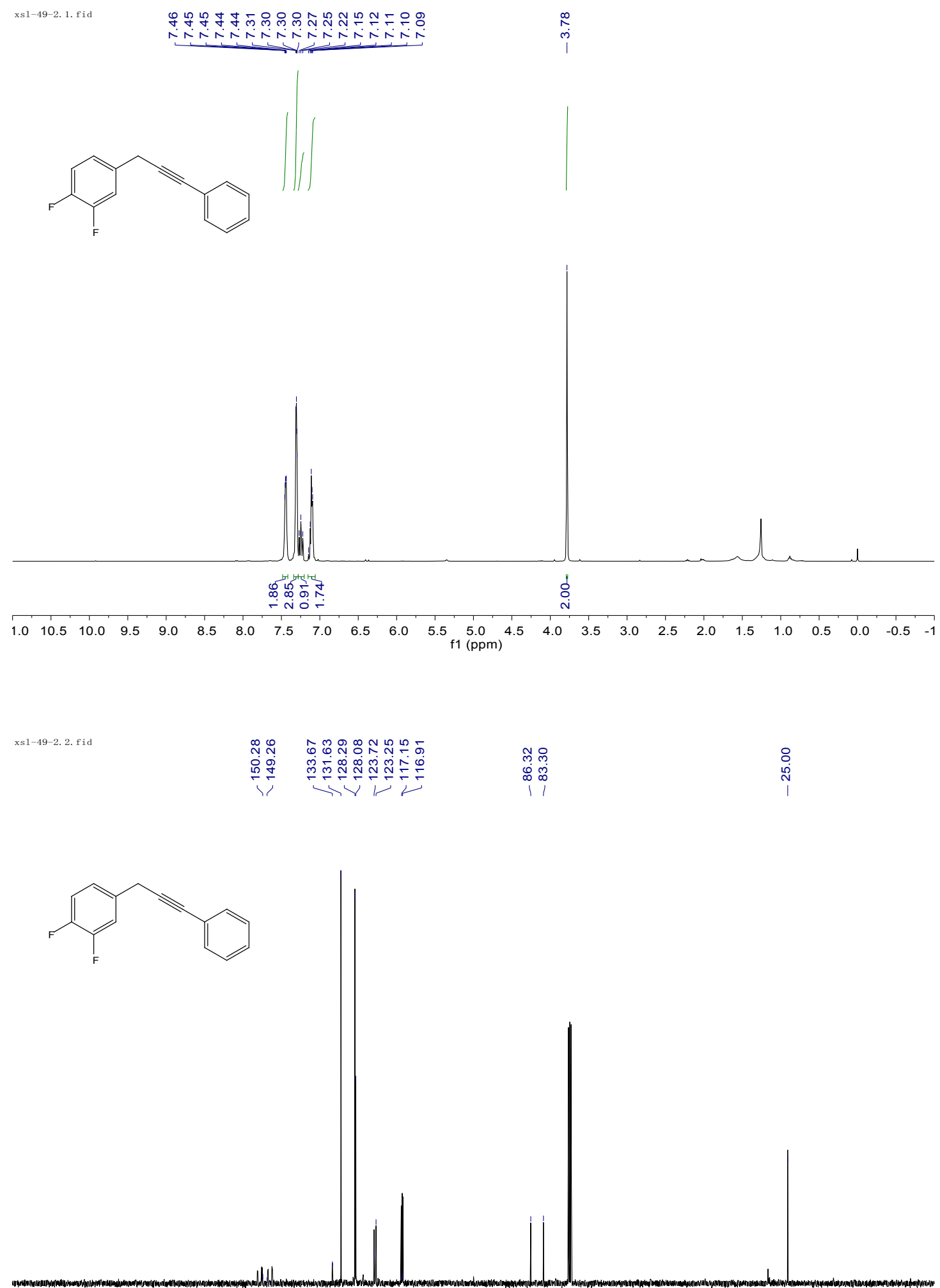

\begin{tabular}{llllllllllllllllllllllll}
\hline 10 & 200 & 190 & 180 & 170 & 160 & 150 & 140 & 130 & 120 & 110 & 100 & 90 & 80 & 70 & 60 & 50 & 40 & 30 & 20 & 10 & 0 & -
\end{tabular}

${ }^{1} \mathrm{H}$ NMR and ${ }^{13} \mathrm{C}$ NMR for compound 3ha 

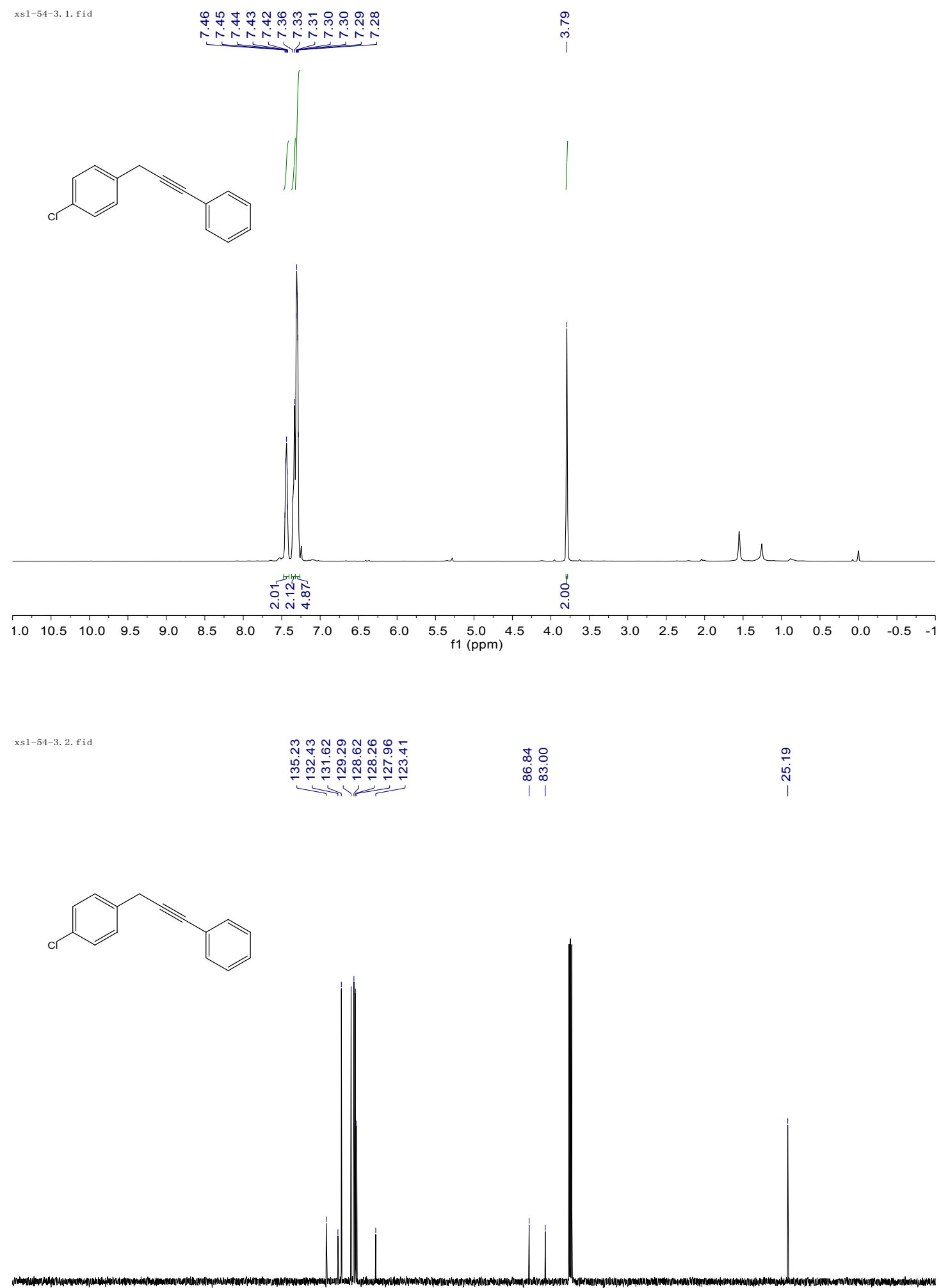

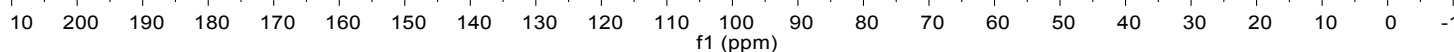

${ }^{1} \mathrm{H}$ NMR and ${ }^{13} \mathrm{C}$ NMR for compound 3ia 


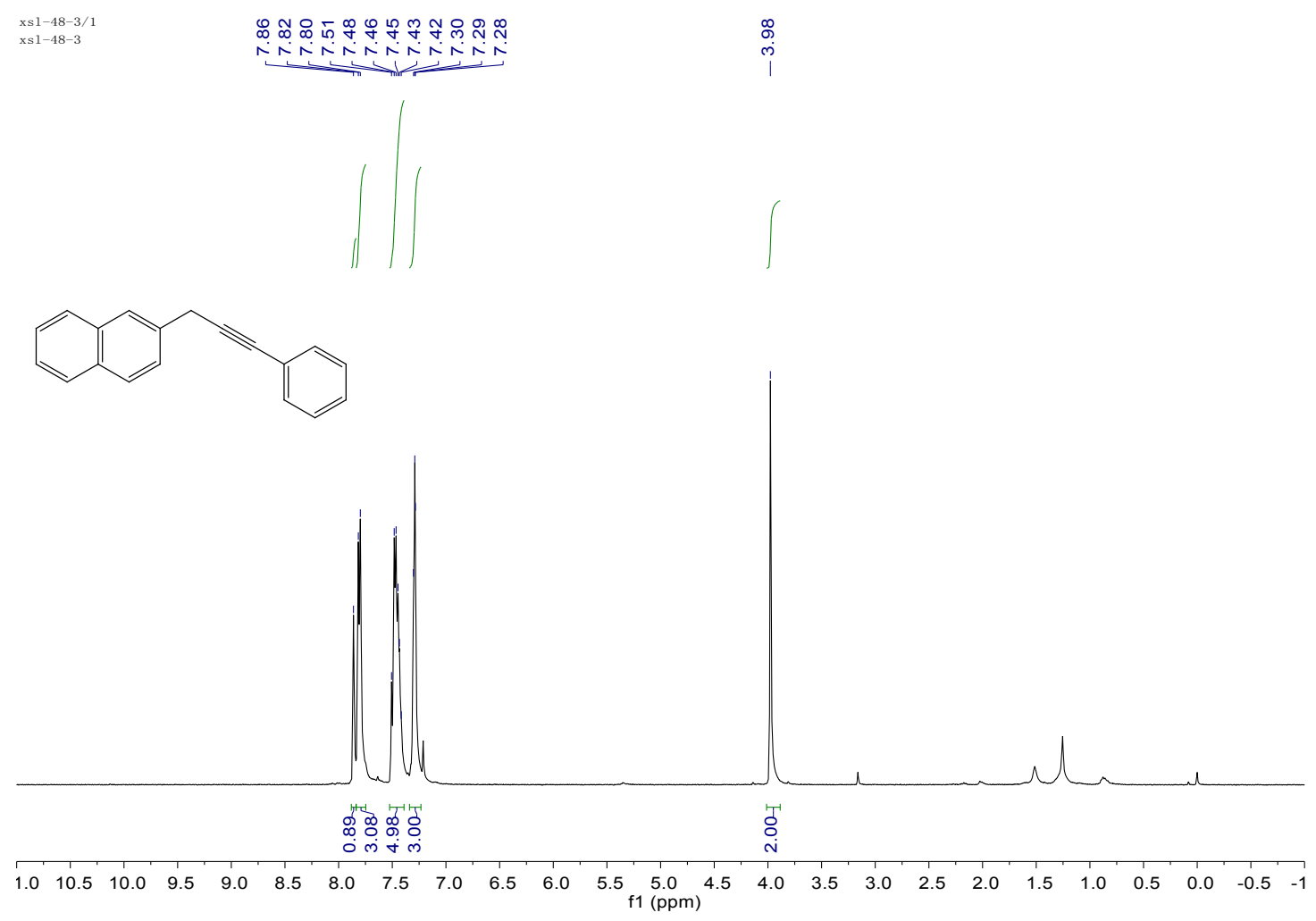

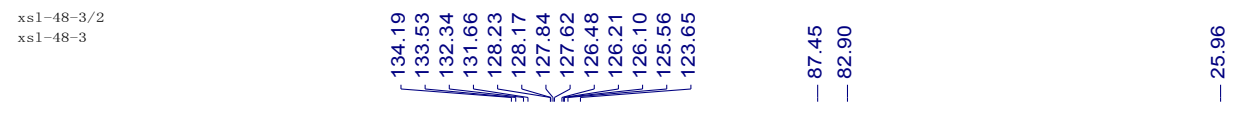

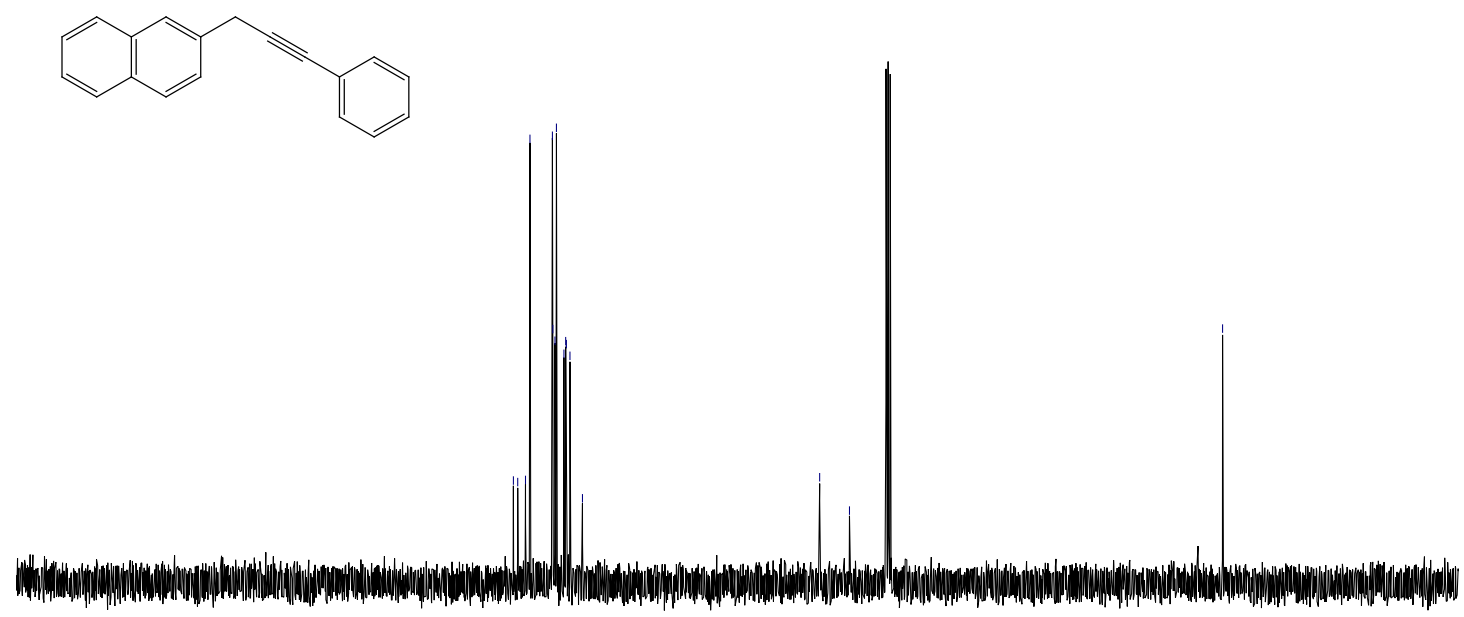

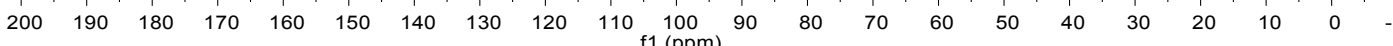

${ }^{1} \mathrm{H}$ NMR and ${ }^{13} \mathrm{C}$ NMR for compound $\mathbf{3 j a}$ 